\title{
The joint influence of personal achievement goals and classroom goal structures on achievement-relevant outcomes
}

Article

Accepted Version

Murayama, K. and Elliot, A. J. (2009) The joint influence of personal achievement goals and classroom goal structures on achievement-relevant outcomes. Journal of Educational Psychology, 101 (2). pp. 432-447. ISSN 0022-0663 doi: https://doi.org/10.1037/a0014221 Available at https://centaur.reading.ac.uk/34835/

It is advisable to refer to the publisher's version if you intend to cite from the work. See Guidance on citing.

To link to this article DOI: http://dx.doi.org/10.1037/a0014221

Publisher: American Psychological Association

All outputs in CentAUR are protected by Intellectual Property Rights law, including copyright law. Copyright and IPR is retained by the creators or other copyright holders. Terms and conditions for use of this material are defined in the End User Agreement. 


\section{CentAUR}

Central Archive at the University of Reading

Reading's research outputs online 
RUNNING HEAD: Joint influence

The Joint Influence of Personal Achievement Goals and Classroom Goal Structures on Achievement-relevant Outcomes

\author{
Kou Murayama \\ Tokyo Institute of Technology
}

Andrew J. Elliot

University of Rochester

Journal of Educational Psychology (2009) 


\begin{abstract}
Herein we provide an analytic framework for studying the joint influence of personal achievement goals and classroom goal structures on achievement-relevant outcomes. This framework encompasses three models (the direct effect model, indirect effect model, and interaction effect model), each of which addresses a different aspect of the joint influence of the two goal levels. These three models were examined together using a sample of 1578 Japanese junior-high and high school students from 47 classrooms. Results provided support for each of the three models: Classroom goal structures were not only direct, but also indirect predictors of intrinsic motivation and academic self-concept, and some cross-level interactions between personal achievement goals and classroom goal structures were observed (indicating both goal match and goal mismatch effects). A call is made for more research that takes into consideration achievement goals at both personal and structural levels of representation.
\end{abstract}


Researchers and theorists in the achievement motivation literature have long recognized the importance of attending to both person- and situation-based factors in predicting affect, cognition, and behavior in achievement settings (Lewin, Dembo, Festinger, \& Sears, 1944; Murray, 1938). In the contemporary literature on achievement goals, this recognition has primarily been manifest in empirical work on the relations among achievement goals, classroom goal structures, and achievement-relevant outcomes. Achievement goals are conceptualized as the purpose or cognitive-dynamic focus of the individual's competence-relevant engagement (Dweck \& Leggett, 1988; Elliot, 1997; Maehr, 1984; Nicholls, 1989). Herein, we use the term personal achievement goals when referring to this individual-level construct. Classroom goal structures are conceptualized as competence-relevant environmental emphases made salient through general classroom practices and the specific messages that teachers communicate to their students (Ames, 1992; Covington \& Omelich, 1984; Epstein, 1988; Maehr \& Midgley, 1996). Both personal achievement goals and classroom goal structures are thought to exert an important influence on students' achievement-relevant outcomes in the classroom, but the precise nature of this joint influence remains unclear. We attend to this surprisingly understudied issue in the present research.

The Joint Influence of Personal Achievement Goals and Classroom Goal Structures: An Analytic Framework

Initial research on personal achievement goals centered on two distinct types of goals: mastery goals, which focus on developing competence through task mastery, and performance goals, which focus on demonstrating competence relative to others (Dweck, 1986; Maehr \& Nicholls, 1980). Elliot and his colleagues (Elliot \& Church, 1997; Elliot \& Harackiewicz, 1996) extended this dichotomous model of personal achievement goals to a trichotomous model. In this extended model, performance goals are differentiated in terms of approach and avoidance, and 
three separate personal achievement goals are identified: (a) mastery goals, which focus on developing competence through task mastery, (b) performance-approach goals, which focus on attaining competence relative to others, and (c) performance-avoidance goals, which focus on avoiding incompetence relative to others. ${ }^{1}$ Empirical work has clearly highlighted the integral role of personal achievement goals in achievement motivation, as the goals in both the dichotomous and trichotomous models have been shown to differentially predict a host of important achievement-relevant outcomes (for reviews, see Dweck, 1999; Elliot, 2005; Harackiewicz, Barron, \& Elliot, 1998; Kaplan \& Maehr, 2007; Payne, Youngcourt, \& Beaubien, 2007; Urdan, 1997).

As with personal achievement goals, research on classroom goal structures initially centered on two distinct types of goals: A mastery goal structure, in which an emphasis is placed on mastery, personal improvement, and understanding in the classroom, and a performance goal structure, in which an emphasis is placed on relative ability and competition in the classroom. Midgley and her colleagues (Midgley et al., 2000) subsequently applied the trichotomous model of personal achievement goals to the classroom context by differentiating the performance goal structure in terms of approach and avoidance. This resulted in three separate classroom goal structures: (a) a mastery goal structure, in which the classroom environment focuses on engaging in academic work in order to develop competence, especially task- and intrapersonally-based competence; (b) a performance-approach goal structure, in which the classroom environment focuses on engaging in academic work in order to demonstrate competence, especially normative competence; and (c) a performance-avoidance goal structure, in which the classroom environment focuses on engaging in academic work in order to avoid demonstrating incompetence, especially normative incompetence. Far less research has been conducted on classroom goal structures than personal achievement goals, and it should be noted that some studies focus on select components 
of mastery- or performance-based goal structures (e.g., lecture engagement as one aspect of a mastery goal structure; Church, Elliot, \& Gable, 2001), rather than full representations of these structures. Nevertheless, the work that has been conducted has clearly documented the importance of this classroom level of analysis in accounting for achievement-relevant outcomes (for reviews, see Anderman, Patrick, Hruda, \& Linnenbrink, 2002; Kaplan, Middleton, Urdan, \& Midgley, 2002; Linnenbrink, 2004; Meece, Anderman \& Anderman, 2006; Pintrich \& Schunk, 2002; Urdan, 2004a; Urdan \& Turner, 2005).

Although the predictive utility of personal achievement goals and classroom goal structures is (reasonably) well-established, the precise way in which these two levels combine to predict achievement-relevant outcomes has received relatively little empirical attention. One purpose of the present research is to provide an analytical framework for studying the joint influence of personal achievement goals and classroom goal structures (see also Linnenbrink, 2004). We believe that providing such a framework will serve two functions: 1) it will help in the organization and interpretation of existing data addressing this topic, and 2) it will help to guide subsequent research endeavors in this area. Figure 1 presents the three models that comprise this analytical framework. In the following, we describe each model, and review existing research relevant to each model.

A direct effect ${ }^{2}$ model (Figure 1a) posits that classroom goal structures directly influence achievement-relevant outcomes. The primary focus of this model is on the direct effect of classroom goal structures per se, but it is also assumed that this effect holds when the influence of personal achievement goals on achievement-relevant outcomes is considered. Several studies in the literature have utilized this model. Some studies have examined the influence of classroom goal structures alone, either without measuring personal achievement goals (Anderman et al., 2001; Ames \& Archer, 1988; Kaplan \& Midgley, 1999; Kumar, 2006; Ryan, Gheen, \& Midgley, 
1998; Ryan \& Patrick, 2001; Turner et al., 2002; Urdan, Midgley, \& Anderman, 1998) or measuring personal achievement goals, but conducting separate sets of analyses for classroom goal structures and personal achievement goals (Gutman, 2006). Other studies have assessed both goal structures and personal goals, and examined their independent influence (Kaplan, Gheen, \& Midgley, 2002; Karabenick, 2004; Lau \& Nie, 2008; Midgley \& Urdan, 1995; 2001; Nolen, 2003; Wolters, 2004). Most of these studies have clearly documented that classroom goal structures directly influence achievement-relevant outcomes, and many have shown that this is the case over and above personal achievement goals.

An indirect effect model (Figure 1b) posits that classroom goal structures indirectly influence achievement-relevant outcomes through their impact on personal achievement goal adoption. The primary focus of this model is on the intermediary role of personal achievement goals in the link between classroom goal structures and achievement-relevant outcomes; goal structures are thought to prompt the adoption of personal goals, and personal goals are viewed as having a proximal influence on outcomes. A number of studies in the literature have used this model, examining paths from goal structures to personal goals to outcomes (Bong, 2005; Church et al., 2001; Greene, Miller, Crowson, Duke, \& Akey, 2004; Nolen \& Haladyna, 1990; Kaplan \& Maehr, 1999; Midgley, Anderman, \& Hicks, 1995; Miki \& Yamauchi, 2005; Patrick, Ryan, \& Kaplan, 2007; Roeser Midgley, \& Urdan, 1996; Urdan, 2004b; Yamauchi \& Miki, 2003). A few of these studies have investigated whether personal goals serve as mediators of direct effects of goal structures on outcomes (see Church et al., 2001; Roeser et al., 1996), but most have simply focused on the sequence of paths from goal structures to personal goals to outcomes. Furthermore, some studies have focused exclusively on the goal structure to personal goal path (Anderman \& Midgley, 1997; Anderman \& Young, 1994; Middleton, Gheen, Midgley, Hruda, \& Anderman, 2000; Urdan, 2004c; Urdan \& Midgley, 2003; Young, 1997). Most studies in this literature have 
yielded support for the indirect effect model: The path between classroom goal structures and personal achievement goals, as well as that between personal achievement goals and achievement-relevant outcomes (controlling for classroom goal structures) has received consistent support; tests of mediation have also tended to yield supportive data.

An interaction effect model (Figure 1c) posits that classroom goal structures moderate the influence of personal achievement goals on achievement-relevant outcomes. The primary focus of this model is on the interactive role of classroom goal structures and personal achievement goals; the influence of personal goal pursuit is thought to vary as a function of the type of goal structure in place within the classroom. Although researchers have sounded the call for research on the interaction between goal structures and personal goals (Linnenbrink, 2005; Urdan, 2001), only a few have responded. In fact, to our knowledge, only three studies have appeared in the literature that have directly tested this type of moderation, those by Wolters (2004), Linnenbrink (2005), and Lau and Nie (2008). Although not the central focus of his research, Wolters (2004) conducted a series of regression analyses testing perceived classroom goal structure x personal achievement goal effects. These analyses yielded few interactions (4 out of 42 interactions tested were significant), and the effects that were obtained were quite small. Linnenbrink (2005) worked with teachers to manipulate classroom goal structures, and examined the interaction between the manipulated goal structures and personal achievement goals assessed prior to the goal structure manipulation. No significant interactions were observed in her study. Lau and Nie (2008), in a large sample questionnaire study, focused on the interaction between perceived classroom goals and personal achievement goals. They found that a strong perceived focus on classroom performance-approach goal structures reinforced (or exacerbated) the associations between personal performance-avoidance goals and student outcomes.

It is important to note that these three models (the direct effect, indirect effect, and 
interaction effect models) are by no means incompatible and can be investigated simultaneously. For example, the indirect effect model is mute on whether classroom goal structures have a direct effect on outcomes; both direct and indirect effects may be documented with the same goal structures and personal goals. In the same way, it is possible that a classroom goal structure both moderates the effects of personal achievement goals and has a direct effect on achievement-relevant related outcomes. Despite the compatibility of these models, no research to date has investigated the three models within the same study. We view this as problematic, because conclusions obtained from a single model may not only be incomplete, but misleading. For example, investigating the direct effect model alone might lead a researcher to conclude that facilitating a certain goal structure is important because it has a direct positive influence on outcomes. It remains possible, however, that this goal structure vitiates the positive influence or exacerbates the negative influence of personal achievement goals on these same outcomes, a possibility that can only be uncovered through examination of the interaction effect model. Therefore, consideration of all three models simultaneously is valuable in that it represents a more thorough and complete analysis than focusing on any of the three models in isolation. This more comprehensive approach holds promise for disentangling the complex nature of the joint influence of personal achievement goals and classroom goal structures on achievement-relevant outcomes.

\section{Methodological Issues}

Research on classroom goal structures has focused primarily on students' perceptions of the achievement context, rather than the objective environment itself. This seems reasonable, given that it is students' perceptions -- the "psychological environment" -- that is presumed to play the most critical role in achievement motivation processes (Ames, 1992; Maehr \& Midgley, 1991). Student perception data is typically examined in one of two ways: 1) using students' 
responses as the unit of analysis, or 2) using the classroom as the unit of analysis by aggregating students' responses within classrooms. Unfortunately, both of these approaches have weaknesses that make straightforward interpretation of results difficult.

The first, student-level, approach is problematic, because it only focuses on differences between individuals without consideration of the classroom level effects of goal structures that have been shown to have unique effects on achievement-relevant outcomes (e.g., Turner et al., 2002; Wolters, 2004). This is the case regardless of whether multiple regression or more sophisticated data analytic techniques such as hierarchical linear modeling (HLM) are used. In addition, when the same students provide both goal structure and personal goal data, an assortment of response biases such as social desirability, acquiescence, and item context effects (e.g., students' ratings of goal structures are influenced by their ratings on the personal goal items, and vice versa), are likely to be present (Podsakoff, MacKenzie, Lee, \& Podsakoff, 2003). These response biases can result in an over- or under-estimation of ratings at either level of goal, and the correlated errors produced by these response biases can inflate correlations among variables (Miller \& Murdock, 2007; see also Harrison \& McLaughlin, 1993; Knowles, 1988; Sudman, Bradburn, \& Schwarz, 1996). This problem is exacerbated when both goal levels are assessed within the same session, which is the case in nearly all existing research. The second, aggregation, approach takes students' specific classrooms into consideration, but does not fully address the response bias problem. Aggregation disperses and, therefore, dilutes response bias, but given that the same individuals rate both types of goal, correlated errors among the ratings will still be present to some degree.

To address the response bias problem in the present research, we randomly divided students into two groups: one group only provided their perceptions of the classroom goal structure, and the other group only reported their personal achievement goals and provided data 
on the focal outcome variables. This approach is somewhat costly in that it reduces the number of student-level units by half, but it has a handsome payoff in that it effectively addresses the response bias problem. We believe that this approach affords a clearer window into the joint effects of classroom- and person-level goals than has heretofore been possible (for a similar approach, see Lau \& Nie, 2008).

\section{The Present Study and Hypotheses}

In the present study, we examined the joint effects of personal achievement goals and classroom goal structures in junior and senior high school students' mathematics classes in Japan. We focused particularly on the interaction effect model given the dearth of existing research on this model, but also investigated the direct and indirect effect models. We used the classroom as the unit of analysis for the goal structures, and split the samples to measure the student level variables and school level variables separately. The achievement-relevant outcomes that we focused on were intrinsic motivation and academic self-concept.

Intrinsic motivation represents enjoyment of and interest in an activity for its own sake (Deci, 1971; Lepper, 1981), and has been identified as an important component of the achievement goal nomological network (Ames, 1992; Harackiewicz \& Sansone, 1991; Heyman \& Dweck, 1992; Nicholls, 1989). Past studies have consistently shown that intrinsic motivation is positively predicted by personal mastery goals and negatively predicted by personal performance-avoidance goals (Elliot \& Church, 1997; Harackiewicz, Barron, Carter, Lehto, \& Elliot, 1997). On the other hand, personal performance-approach goals have shown mixed results (for reviews, Harackiewicz et al., 1998; Rawsthorne \& Elliot, 1999), which suggests the likely presence of moderator variables. As such, intrinsic motivation seems ideally suited for examining interaction effects. Academic self-concept is a competence judgment coupled with an evaluative reaction regarding self-worth in the academic domain (Marsh, 1990). In contrast to intrinsic 
motivation, there are few existing studies that have investigated academic self-concept from the perspective of the trichotomous achievement goal model (Pajares, Britner, \& Valiante, 2000; Pajares \& Cheong, 2003; Skaalvik, 1997). However, academic self-concept is widely considered an important outcome in achievement settings (see Marsh \& Hau, 2003), and examining it in our research will help redress the problem of its relative oversight in prior work.

On the basis of prior research and theory relevant to the direct effect model (e.g., Anderman et al., 2001; Kumar, 2006; Lau \& Nie, 2008; Ryan et al., 1998; Turner et al., 2002; Urdan et al., 1998), we anticipated that perceived mastery goal structures would be direct positive predictors of intrinsic motivation and, perhaps, academic self-concept as well. Perceived performance-based goal structures were posited to be direct negative predictors of the focal outcome variables. These relations were expected to be observed over and above the influence of personal achievement goals on these outcomes. Personal mastery goals were expected to yield relations similar to those produced by their structural counterparts (Elliot \& Church, 1997; Church et al., 2001; Harackiewicz et al., 1997; Pintrich \& Garcia, 1991), whereas personal performance-approach goals were expected to be positive predictors, or to be unrelated to, intrinsic motivation and academic self-concept, and personal performance-avoidance goals were expected to be negative predictors of both outcomes (Cury, Elliot, Sarrazin, Da Fonseca \& Rufo, 2002; Elliot \& Church, 1997; Pajares et al., 2000; Skaalvik, 1997; Zusho, Pintrich, \& Cortina, 2005). Likewise, on the basis of prior research and theorizing relevant to the indirect effect model (Anderman \& Midgley, 1997; Bong, 2005; Greene et al., 2004; Kaplan \& Maehr, 1999; Miki \& Yamauchi, 2005; Patrick et al., 2007; Urdan, 2004b; Yamauchi \& Miki, 2003), we anticipated that the perceived goal structures would prompt the adoption of their corresponding person-level goal. These personal goals were posited to (at least partially) mediate any observed direct relations between perceived goal structures and achievement-relevant outcomes (e.g., Church et 
al., 2001; Roeser et al., 1996).

Given the dearth of research and theory on the interaction effect model, we were hesitant to offer specific hypotheses a priori. We were most interested in two general hypotheses, a match hypothesis and a mismatch hypothesis. With regard to a match hypothesis, many theorists over the years have posited various instantiations of a match hypothesis that share in common the idea that optimal outcomes are expected when there is congruence between personal characteristics and characteristics of the social environment (Bretz \& Judge, 1994; Carver \& Scheier, 1981; Cronbach \& Snow, 1981; Eccles et al., 1993; Higgins,, 2000; Hunt, 1975; Lewin, 1935; Murray, 1938; Oishi, Diener, Suh, \& Lucas, 1999; Vansteenkiste, Simons, Lens, Sheldon, \& Deci, 2004). Achievement goal theorists have also set forth different types of match hypotheses. Specifically, these theorists have proposed that personal achievement goals, be they mastery- or performance-based, have their most positive influence on achievement-relevant outcomes when they match the focus of one's upper level goals (Harackiewicz \& Elliot, 1998; Harackiewicz \& Sansone, 1991), one's achievement dispositions (Durik \& Harackiewicz, 2003; Elliot \& Harackiewicz, 1994; Harackiewicz \& Elliot, 1993), or the achievement environment (Barron \& Harackiewicz, 2001; Kristof-Brown \& Stevens, 2001; Sansone, 1989; see also El-Alayli, 2006), including the classroom environment (Lau \& Nie, 2008; Linnenbrink, 2005; Linnenbrink \& Pintrich, 2001).

For achievement goal structures and personal achievement goals, approach-based personal goals may indeed have their most positive influence on achievement-relevant outcomes when they match the focus of the classroom goal structure. However, a different pattern may be likely for avoidance-based goal structures and personal goals. In this instance, a match may not produce the most positive results, but may instead exacerbate the negative implications of pursuing avoidance-based personal goals (see also Lau \& Nie, 2008). To the extent that this 
occurs, it would suggest that the match hypothesis should be stated in terms of accentuation (congruence accentuates the basic pattern) rather than positivity (congruence produces the optimal pattern; see Elliot et al., 2005, for a conceptual parallel).

Mismatch hypotheses are not as prevalent in the literature as match hypotheses, and are typically assumed to represent the reciprocal of the proposed match hypotheses. However, this need not be the case, and it is informative to consider different mismatches between goal structures and personal goals, and their possible implications, of their own accord. A first possibility is that the beneficial influence of personal goals is vitiated (a "vitiation effect") in the context of a mismatched goal structure (see Lau \& Nie, 2008). For example, personal mastery goals may have a weaker positive influence on outcomes in the context of a performance-based goal structure, or personal performance-approach goals may have a weaker positive influence on outcomes in the context of a mastery goal structure. A second possibility is that the inimical influence of personal goals is mitigated (a "mitigation effect") in the context of a mismatched goal structure. For example, personal performance-avoidance goals may not be as problematic in the context of a mastery goal structure (a form buffering effect; see Linnenbrink, 2005). A third possibility is that the inimical influence of personal goals is exacerbated (an "exacerbation effect") in the context of a mismatched goal structure. For example, personal performance-avoidance goals may have a particularly negative influence on outcomes in the context of a performance-approach goal structure.

In sum, in the empirical component of the present work, we sought to examine the direct effect, indirect effect, and interaction effect models within the same study. We did so using the trichotomous achievement goal framework in junior and senior high school classrooms in Japan, focusing specifically on the joint influence of classroom goal structures and personal achievement goals on intrinsic motivation and academic self-concept. 
Method

\section{Participants and Procedure}

The sample consisted of Japanese junior and senior high school students in 47 classrooms (20 junior high, 27 senior-high) in 11 schools. Schools were recruited by contacting school administrators in Tokyo and the Kanto region of Japan; schools with diverse economic and achievement levels were selected for the study. From an original sample of 1,641 students, 63 were excluded prior to data analysis because they made inappropriate responses to the items (e.g., filling in the same value across all items or repeating a systematic pattern such as $123454321 \ldots$. .). This brought the final sample to 1,578 students (738 male, 834 female, 6 unspecified). The sample included $6.2 \%$ seventh-grade students, $23.8 \%$ eighth-grade students, $13.6 \%$ ninth-grade students, $36.2 \%$ tenth-grade students, $9.9 \%$ eleventh-grade students, and $10.1 \%$ twelfth-grade students.

A questionnaire was administered in November, 2006, during students' regularly scheduled mathematics class. In Japan, the new school year begins in April, therefore, sufficient time had clearly passed for classroom goal structures to be established. In each participating classroom, students were randomly assigned to one of two groups. One group, comprised of 788 students, completed a questionnaire containing personal achievement goal and achievement-relevant outcome items, and another group, comprised of 790 students, completed a questionnaire containing classroom goal structure items. The number of individuals completing student-level variables and school-level variables per class ranged from 8 to 22 and 6 to 20, respectively. Students were assured that their responses would be kept confidential, and that no one at home or school would have access to their responses.

\section{Measures}

The personal achievement goal, classroom goal structure, and outcome variables were all 
assessed via questionnaire. All questionnaire items used a 5-point scale, ranging from 1 (not at all true) to 5 (very true). Each variable in the study was specific to the domain of mathematics. Math was chosen as the focus of study, because prior research on achievement goals in secondary schools has found this to be a particularly important and fruitful domain of inquiry (e.g., Anderman, Anderman, \& Griesinger, 1999; Midgley \& Urdan, 2001; Miller, Greene, Montalvo, Ravindran, \& Nichols, 1996; Skaalvik, 1997; Wolters, 2004).

Personal achievement goals. Tanaka and Yamauchi’s (2000) 16 item achievement goal questionnaire was used to assess students' adoption of personal achievement goals for their math class. Tanaka and Yamauchi's (2000) measure is a Japanese version of Elliot and Church's (1997) measure that has been modified with an eye toward junior and senior high school classes in Japan. The reliability and validity of this measure have been demonstrated in prior research (Tanaka \& Yamauchi, 2000; 2001). It consists of six mastery goal items (sample item: "It is important for me to understand the content of this course as thoroughly as possible"), six performance-approach goal items (sample item: "It is important to me to do well compared to others in this class"), and four performance-avoidance goal items (sample item: "I just want to avoid doing poorly in this class"; Tanaka and Yamauchi deleted two items from the Elliot and Church scale on the basis of psychometric analyses). Coefficient omega estimates of reliability (McDonald, 1999) were calculated using the within-classroom covariance matrix ${ }^{3}$; these estimates showed an acceptable degree of internal consistency for each personal achievement goal $(\omega=.74, .84$, and .74 for mastery goals, performance-approach goals, and performance-avoidance goals, respectively).

Classroom goal structures. To assess classroom goal structures, items were translated from the Patterns of Adaptive Learning Survey (PALS; Midgley et al., 2000) and back-translated to assure the meaning of the original scale was maintained. The reliability and validity of the 
classroom goal structure scales of the PALS have been established in prior research (Anderman \& Midgley, 2002). The six items assessing mastery goal structure asked students to rate the extent to which their math class emphasized learning and developing competence (sample item: "In our class, how much you improve is really important."). The four items assessing performance-approach goal structure asked students to rate the extent to which their class emphasized performance and demonstrating ability (sample item: "In our class, getting good grades is the main goal'). The four items assessing performance-avoidance goal structure asked students to rate the extent to which their class emphasized not performing poorly relative to others (sample item: "In our class, it's important not to do worse than other students") 4 .

The items were averaged within classrooms to create classroom-level indices of the three types of goal structure. Coefficient omega estimates of reliability for these aggregated scores were acceptable $(\omega=.75$ for mastery, .85 for performance-approach, and .86 for performance-avoidance goals).

Intrinsic motivation. Items translated from Elliot and Church's (1997) intrinsic motivation scale were used to assess students' intrinsic motivation for their math class (sample item: "I am enjoying this class very much"). The items were back-translated to assure that the meaning of the original scale was maintained. The reliability and validity of this measure has been documented in prior studies (e.g., Cury, Elliot, Da Fonseca, \& Moller, 2006; Elliot \& Church, 1997). The original scale consists of eight items; two items were omitted a priori because they were not relevant to math classes in Japanese junior and senior high school (e.g., "I intend to recommend this class to others"). Coefficient omega, calculated on the basis of the within-covariance matrix, showed good internal consistency $(\omega=.90)$.

Academic self-concept. The Japanese version of Ichihara and Arai's (2004a) scale was used to assess students' academic self-concept in math (sample item: "I get good marks in 
mathematics"). This scale consisted of six items based on Marsh's (1990) Academic Self Description Questionnaire I and II. The measure has been shown to have good reliability and validity in prior research (Ichihara \& Arai, 2004b; Toyama, 2006). Coefficient omega based on the within-covariance matrix showed good internal consistency $(\omega=.88)$.

Control variables. School grade and sex have been shown to be important predictors of motivational and achievement-relevant outcome variables in prior research (for reviews, Eccles \& Midgley, 1989; Hyde \& Durik, 2005). Thus, we collected school grade and sex data from participants so that this information could be controlled for in the analyses ${ }^{5}$. School grade was coded such that "0" reflected seventh-grade, "1" reflected eighth-grade, etc.; sex was dummy coded, with 0 representing males and 1 representing females.

\section{Results}

\section{Descriptive Statistics and Zero-Order Correlations}

Descriptive statistics and within-class level correlations among the student-level variables are presented in Table 1 . The zero-order correlation between the aggregated level-2 variables are $.31(p<.05)$ for mastery and performance-approach goal structures, $-.10(n s)$ for mastery and performance-avoidance goal structures, and $.34(p<.05)$ for performance-approach and performance-avoidance goals structures.

\section{Analysis Plan}

We analyzed the data using hierarchical linear modeling (HLM), with students at level 1 and classrooms at level 2. First, we conducted preliminary analyses in which we partitioned the total variance of the reported classroom goal structures and dependent variables into within-classroom and between-classroom components. Second, we examined the interaction effect model. Specifically, we performed two successive analyses: One analysis tested whether the influence of the student-level predictors (i.e., personal achievement goals) on outcomes varied 
between classrooms (the random coefficient regression model), and the other analysis included the classroom-level predictors (i.e., classroom goal structures) to account for between-classroom variation in the effects of personal achievement goals (the slopes-as-outcomes model). Third, we examined the direct and indirect effect models. For all analyses, the solutions were generated on the basis of full maximum-likelihood estimation using HLM 6 (Raudenbush, Bryk, Cheong, \& Congdon, 2004).

In all subsequent analyses, a multiple imputation technique was used to deal with missing values (Little \& Rubin, 1987). This approach results in less bias than alternative procedures such as listwise deletion or mean substitution (Schafer, 1997; Schafer \& Graham, 2002). The SAS multiple imputation procedure, performed with the Markov Chain Monte Carlo (MCMC) method of imputation, was used to generate five imputed data sets. All HLM analyses were first conducted with the five complete data sets, and the integrated results are reported (Raudenbush \& Bryk, 2002).

\section{Preliminary Analyses}

Fully unconditional HLM models were conducted in preliminary analyses. These models are equivalent to unbalanced one-way random-effects ANOVAs, and enable estimation of the between-classroom and within-classroom variances (Hofmann, Griffin, \& Gavin, 2002).

The analyses examined whether the classroom goal structures significantly varied between classrooms. Mean-level differences between classrooms on the goal structure measure would indicate the existence of coherent classroom-level goal structures (Urdan, 2004c). The results revealed that the two approach forms of goal structure significantly varied between classrooms: Mastery goal structure, $\chi^{2}(46)=98.29, p<.01$; performance-approach goal structure, $\chi^{2}(46)=76.21, p<.01$. Adjusted intraclasss correlations (ICCs) for these classroom goal 
structures were $11 \%$ and $8 \%$, respectively.

In contrast to the two approach-based goal structures, there was no significant variance between classrooms in performance-avoidance goal structure, $\chi^{2}(46)=50.91, n s$. This null finding is consistent with results reported by Kaplan, Gheen, et al. (2002), and following these researchers, we omitted the performance-avoidance goal structure variable in all subsequent analyses.

We also examined whether our dependent variables (intrinsic motivation and academic self-concept) significantly varied between classrooms, and found significant between-classroom variances; for intrinsic motivation, $\chi^{2}(46)=170.13, p<.01$; for academic self-concept, $\chi^{2}(46)=$ 98.47, $p<.01$. The adjusted ICCs were $18 \%$ and $11 \%$, respectively.

\section{Test of the Interaction Effect Model}

Random coefficient regression model. First, we specified a random coefficient regression model with the three personal achievement goals as simultaneous predictors of intrinsic motivation and academic self-concept. The slopes of the predictors were first allowed to vary across classrooms, then nonsignificant random effects were dropped from the model for reasons of statistical efficiency and computational stability (Raudenbush \& Bryk, 2002). All of the predictors were group-mean centered based on the fact that we were interested in the cross-level interactions in the analysis (Enders \& Tofighi, 2007). School grade was included as a classroom-level predictor of intercepts; sex was included as a fixed-effect predictor of the outcome variables. Both variables were left uncentered to facilitate interpretation of the results.

The results are reported in Tables 2 (for intrinsic motivation) and 3 (for academic self-concept). The intercept coefficient represents the expected score of the outcome variable for a seventh-grade male student who has group-mean scores for all personal achievement goals in the 
classroom. The fixed effect coefficients for the student-level predictors represent the average personal achievement goal slopes for the population of classrooms.

For intrinsic motivation, personal mastery goals were a positive predictor $\left(\gamma_{20}=0.80, p\right.$ $<.01)$, whereas personal performance-avoidance goals were a negative predictor $\left(\gamma_{40}=-0.16, p\right.$ $<.01)$. The fixed effect of personal performance-approach goals was also significant, albeit small $\left(\gamma_{30}=0.12, p<.05\right)$; more importantly, the slope of personal performance-approach goals varied significantly across classrooms (variance of $u_{3 \mathrm{j}}=.017, p<.05$ ). Therefore, the results indicate that in some classrooms the effect of personal performance-approach goals was positive, whereas in other classrooms it was null or negative. The slopes of personal mastery and personal performance-avoidance goals did not evidence significant variation between classrooms.

For academic self-concept, personal mastery and personal performance-approach goals were positive predictors $\left(\gamma_{20}=0.46, p<.01 ; \gamma_{30}=0.39, p<.01\right)$, whereas personal performance-avoidance goals were a negative predictor $\left(\gamma_{40}=-0.28, p<.01\right)$. In addition, the slopes of personal performance-approach and personal performance-avoidance goals varied significantly across classrooms (variance of $u_{2 \mathrm{j}}=.033, p<.05$, and variance of $u_{3 \mathrm{j}}=.036, p<.01$, respectively), indicating that the relation between these goals and academic self-concept was different from classroom to classroom. No significant variation was observed in the personal mastery goal slopes.

Slopes-as-outcomes model. To examine the slopes-as-outcomes model, classroom goal structures were added to the random coefficient regression model when there was significant between-classroom variance in the intercepts or slopes ${ }^{6}$. Classroom goal structures were grand-mean centered, and nonsignificant predictors were omitted from the model.

With regard to intrinsic motivation, the relation between personal performance-approach 
goals and intrinsic motivation was shown to vary as a function of the performance-approach and mastery goal structures of the classrooms (see Table 4). Specifically, the performance-approach goal structure was a significant positive predictor of the personal performance-approach goal slope $\left(\gamma_{32}=0.36, p<.05\right)$, whereas the mastery goal structure was a significant negative predictor of this slope $\left(\gamma_{31}=-0.44, p<.05\right)$. These classroom-level variables accounted for a large portion of the between-classroom variance in slopes $(44 \%)$.

To estimate the specific nature of these interactions, we conducted simple slope analyses that tested the significance of the personal achievement goal slopes at goal structure values one standard deviation above and below the sample mean (Bauer \& Curran, 2005; Tate, 2004). The performance-approach goal structure analyses revealed that personal performance-approach goals were a positive predictor of intrinsic motivation within a strong performance-approach goal structure (estimated beta $=0.21, p<.01$ ), but were unrelated to intrinsic motivation within a weak performance-approach goal structure (estimated beta $=0.01, p=.88$ ). The mastery goal structure analyses revealed that personal performance-approach goals were unrelated to intrinsic motivation within a strong mastery goal structure (estimated beta $=0.02, p=.71$ ), but were a positive predictor of intrinsic motivation within a weak mastery goal structure (estimated beta $=$ $0.20, p<.05)$. A pictorial summary of these simple slope results is provided in Figure 2.

With regard to academic self-concept, the relation between both personal performance-approach and personal performance-avoidance goals and academic self-concept varied as a function of the performance-approach goal structure of the classrooms (see Table 5). Specifically, the performance-approach goal structure was a significant positive predictor of the personal performance-approach goal slope $\left(\gamma_{32}=0.46, p<.05\right)$, and was a significant negative predictor of the personal performance-avoidance goal slope $\left(\gamma_{42}=-0.38, p<.05\right)$. The 
performance-approach goal structure accounted for $36 \%$ and $25 \%$ of the between-classroom variance in the slopes of personal performance-approach and personal performance-avoidance goals, respectively.

We used simple slope analyses to estimate the specific nature of the observed interactions. One set of analyses revealed that personal performance-approach goals were a positive predictor of academic self-concept within a weak performance-approach goal structure (estimated beta $=0.25, p<.01$ ), and that this relation was enhanced within a strong performance-approach goal structure (estimated beta $=0.51, p=.01$ ). The other set of analyses revealed that personal performance-avoidance goals were a negative predictor of academic self-concept within a weak performance-approach goal structure (estimated beta $=-0.16, p<.05$ ), and that this relation was exacerbated within a strong performance-approach goal structure (estimated beta $=-0.38, p=.01$ ). A pictorial summary of these simple slope results is provided in Figure 3.

Control variables. Throughout the primary analyses, we found significant negative effects of school grade on intrinsic motivation and academic self-concept (see Tables 2-5). These findings are consistent with prior research, in which a decline has been observed in students' intrinsic motivation (Gottfried, Fleming, \& Gottfried, 2001; Harter, 1981; Otis, Grouzet, \& Pelletier, 2005) and academic self-concept (De Fraine, Van Damme, \& Onghena, 2007; Liu, Wang, \& Parkins, 2005; Meece, Parsons, Kaczala, Goff, \& Futterman, 1982) as students progress through grade levels. A significant sex effect on students' academic self-concept was also found, indicating that female students had a lower academic self-concept in mathematics than male students (see Table 3 and 5). This sex difference favoring male students in the domain of mathematics has repeatedly been found in prior research (Marsh, 1989; Marsh \& Yeung, 1998; Meece et al., 1982; see also Spencer, Steele, \& Quinn, 1999) and is consistent with data showing 
that males tend to perform better than females in mathematics at the grade levels under consideration (Organization for Economic Cooperative Development, 2004).

\section{Direct Effect and Indirect Effect Models}

Direct effect model. The analyses used to test the interaction effect model appear to include a test of the direct effect model, because classroom goal structures, as well as personal achievement goals, are included to explain the between-classroom variance in the intercepts. However, as Enders and Tofighi (2007) point out, grand-mean centering, rather than group-mean centering, is appropriate when one is primarily interested in a level 2 predictor and wants to control for level 1 effects. Accordingly, we tested the direct effect model with the same model described in Table 4 and Table 5, but using grand-mean centering for level-1 predictors. Results showed that mastery and performance-approach goal structures were significant predictors of the average level of students' intrinsic motivation. The mastery goal structure was a positive predictor of intrinsic motivation $\left(\gamma_{02}=0.74, p<.01\right)$, whereas the performance-approach goal structure was a negative predictor $\left(\gamma_{03}=-0.36, p<.01\right)$. The goal structures accounted for $42 \%$ of the between-classroom variance in the average level of intrinsic motivation. In similar fashion, the average level of academic self-concept was negatively predicted by the performance-approach goal structure $\left(\gamma_{03}=-0.38, p<.01\right)$. However, mastery goal structure was not a significant predictor of the average level of academic self-concept $\left(\gamma_{02}=0.12, n s\right)$. The goal structures accounted for $19 \%$ of the between-classroom variance in the average level of academic self-concept. Thus, in classrooms where the focus was on mastering tasks, the average level of students' intrinsic motivation was high, whereas in classrooms where the focus was on outperforming others, the average level of students' intrinsic motivation and academic self-concept was low. 
Indirect effect model. Multilevel mediation analyses were used to test the indirect effect model (Krull \& MacKinnon, 1999; 2001), because the commonly used ordinary least squares method has been shown to underestimate the standard errors of indirect effects in analyzing hierarchically organized data. Level 1 predictors were grand-mean centered (Enders \& Tofighi, 2007). School grade and sex were controlled in the analyses, as in the testing of the other models.

First, we specified an HLM model with classroom goal structures as classroom-level predictors of personal achievement goals; intercepts were treated as random. The results revealed that a mastery goal structure positively predicted personal mastery goals $(\gamma=0.77, p<.01)$. On the other hand, neither a mastery goal structure, nor a performance-approach goal structure, significantly predicted personal performance-approach or personal performance-avoidance goals.

Second, we specified a second HLM model with classroom goal structures as classroom-level predictors of intrinsic motivation and academic self-concept. The results indicated that a mastery goal structure is a positive predictor of intrinsic motivation $(\gamma=1.35, p$ $<.01)$ and academic self-concept $(\gamma=0.56, p<.05)$, whereas a performance-approach goal structure is a negative predictor of intrinsic motivation $(\gamma=-0.62, p<.01)$ and academic self-concept $(\gamma=-0.49, p<.01)$.

Finally, we specified a third HLM model in which both achievement goal structures and personal mastery goals were included as predictors of the outcome variables (personal performance-approach and personal performance-avoidance goals were not included, because they were not significantly predicted by the classroom goal structures). The intercept term was specified as a random coefficient; personal mastery goal effects were treated as fixed, because there was no significant variation between classrooms in these goals. The results indicated that personal mastery goals were a positive predictor of intrinsic motivation $(\gamma=0.82, p<.01)$ and 
academic self-concept $(\gamma=0.55, p<.01)$, which, together with the result from the first HLM model, points to the role of personal mastery goals as an intervening variable. Accordingly, we examined the indirect effect of a mastery goal structure on the outcome variables through personal mastery goals using Sobel's (1982) test (Krull \& Mackinnon, 1999; 2001). The indirect effects were significant for both outcomes: $z=3.19, p<.01$, for intrinsic motivation; $z=3.14, p$ $<.01$, for academic self-concept. The gamma coefficient for the direct influence of mastery goal structure on academic self-concept was no longer significant $(\gamma=0.13, n s)$, with a gamma decrease of $76 \%$, as opposed to the original estimates $(0.56)$; this indicates full mediation. The gamma coefficient for the direct influence of mastery goal structure on intrinsic motivation was $0.72(p<.01)$ as opposed to the original 1.35, with a gamma decrease of $47 \%$.

\section{Discussion}

The present research provides an analytic framework for studying the joint influence of personal achievement goals and classroom goal structures on achievement-relevant outcomes. This framework is comprised of three models -- the direct effect model, the indirect effect model, and the interaction effect model -- each of which addresses a different aspect of the joint influence of the two levels of goals on outcomes. Given that each of the three models in our analytic framework provides data on a different research question, results from all three models must be considered together to acquire a complete understanding of how goal structures and personal goals operate to produce outcomes. In the following, we overview the main results that emerged from each model, consider how these findings fit together to form an overall picture, and then discuss the limitations of our research and suggest future directions for research in this area.

\section{Direct, Indirect, and Interaction Effect Models}

The results from the direct effect model indicated that a mastery goal structure was a 
direct positive predictor of intrinsic motivation, whereas a performance-approach goal structure was a direct negative predictor of intrinsic motivation and academic self-concept. Each of these results was observed independently of the influence of personal achievement goals. This pattern of findings is consistent with a number of studies in the existing literature, albeit for a different set of outcome variables (see Kaplan, Gheen et al., 2002; Karabenick, 2004; Midgley \& Urdan, 2001). Personal mastery goals yielded relations similar to those produced by their structural counterparts, whereas personal performance-approach goals were positive predictors of intrinsic motivation and academic self-concept, and personal performance-avoidance goals were negative predictors of both outcomes. These links between each of the personal achievement goals and the achievement-relevant outcomes are entirely consistent with those reported in the existing literature (for intrinsic motivation, see Cury et al., 2002; Elliot \& Church, 1997; Harackiewicz et al., 1997; Zusho et al., 2005; for academic self-concept, see Pajares et al., 2000; Pajares \& Cheong, 2003; Skaalvik, 1997).

Two notes should be made with regard to the direct effect model results. First, despite the fact that there is evidence accumulating in support of the direct influence of goal structures on outcomes (the present study inclusive), it is not clear how a goal structure can influence motivation and outcomes without the mediational role of personal achievement goals (Urdan, 2004a). Future research would do well to seek to identify other possible mediators of such direct relations. Second, although we did not find a direct link between mastery goal structure and academic self-concept, this does not mean that there is absolutely no relation between these two variables. As is clear from the results for the indirect effect model described below, mastery goal structure has an indirect influence on academic self-concept. This nicely illustrates the point, to be reiterated shortly, that focusing solely on the direct effect model alone is not sufficient to capture the complete picture of the joint influence of personal achievement goals and goal 
structures on outcomes.

The results from the indirect effect model indicated that a mastery goal structure was a positive predictor of students' adoption of personal mastery goals, but that a performance-approach goal structure was not related to achievement goal adoption of any sort. The finding regarding mastery goals is consistent with the existing literature (Bong, 2005; Church et al., 2001; Roeser et al., 1996), and allowed an examination of the mediational role of personal mastery goals. The data indicated that these goals indeed served as a partial (for intrinsic motivation) and a full (for academic self-concept) mediator of the relationship between mastery goal structure and achievement-relevant outcomes. These findings represent a conceptual replication (for intrinsic motivation) and extension (for academic self-concept) of the work of Church et al. (2001; see also Roeser et al., 1996).

The null result for performance-approach goals may seem surprising, because other researchers have found that a performance-approach goal structure leads to the adoption of personal performance-approach goals (Midgley et al., 1995; Urdan, 2004b; Young, 1997). However, this apparent discrepancy might be due to methodological differences. Most previous research examining the indirect effect model and showing a link between classroom goal structures and corresponding person-level goals has used students' responses as the unit of analysis for the indices of classroom goal structure (Bong, 2005; Church et al., 2001; Greene et al., 2004; Nolen \& Haladyna, 1990; Kaplan \& Maehr, 1999; Midgley et al., 1995; Roeser et al., 1996; Urdan, 2004c; Young, 1997). This method introduces various forms of response bias, resulting in an inflation of regression coefficients or correlations (Miller \& Murdock, 2007). In our work, we used the classroom as the unit of analysis by aggregating students' responses within classrooms for the indices of classroom goal structure. Only a few studies have adopted this classroom-level approach, and those that have done so have found goal structures to be rather 
weak predictors of person-level goals (Anderman \& Young, 1994; Urdan, 2004b). In addition, we assessed student-level variables and classroom-level variables in separate groups, which undoubtedly further excluded the effects of response biases and provided a clearer picture of the focal relations. Future research is needed to more fully examine the link between classroom goal structures and personal achievement goals to determine the extent to which these relations exit independent of response biases, and to see how the unit of analysis examined affects the results obtained.

The results from the interaction effect model, which only a few studies have tested thus far, indicated support for both match and mismatch hypotheses. Regarding the match hypothesis, we found that the relation between personal performance-approach goals and outcomes was moderated by a performance-approach goal structure: Personal performance-approach goals were a positive predictor of intrinsic motivation, but this was only the case in classrooms with a strong performance-approach goal structure. Personal performance-approach goals were also a positive predictor of academic self-concept, and this was particularly the case in classrooms with a strong performance-approach goal structure. It should be noted, however, that the interaction between personal performance-avoidance goals and performance-avoidance goal structures was not observed (it could not be tested, given the lack of significant variation between classrooms for the performance-avoidance goal structure). Therefore, it remains unclear whether the match hypothesis is best stated in terms of accentuation (congruence accentuates the basic pattern) or positivity (congruence produces optimal pattern).

Of particular importance here is that the match effect was observed only for performance-approach goals. We think that this finding may have both empirical and conceptual significance. On the empirical front, personal performance-approach goals have a varied empirical profile, in that sometimes they are linked to positive outcomes, sometimes they produce 
null results, and occasionally they are linked to negative outcomes (for a review, see Elliot \& Moller, 2003). The varied pattern of findings is likely due to a number of different sources, and our results suggest that one such source is the classroom goal structure. Thus, one answer to the pressing question "When are (personal) performance-approach goals adaptive?" appears to be that they are adaptive in (at least some) competitive contexts. On the conceptual front, the hierarchical model of achievement goals suggests that performance-approach goals are undergirded by both adaptive (approach) and maladaptive (avoidance) forms of motivation (Elliot, 2006; Elliot \& Church, 1997). Therefore, whether performance-approach goals promote or disrupt adaptive self-regulation is presumed to depend, in part, on which types of underlying motivation is operative in a given situation. Performance-approach goal structures, which emphasize competitive striving and provide normative competence feedback, undoubtedly activate the need for achievement for those dispositionally inclined toward the pride of successful accomplishment, and this underlying appetitive motivation would be expected to support persistent and effortful pursuit of performance-approach goals.

Regarding the mismatch hypothesis, we observed two different types of mismatch effects: Personal performance-approach goals were a positive predictor of intrinsic motivation in classrooms with a weak mastery goal structure, but they were unrelated to intrinsic motivation in classrooms with a strong mastery goal structure, and personal performance-avoidance goals were a negative predictor of academic self-concept in general, but this relation was particularly strong in classrooms with a strong performance-approach goal structure. Therefore, a goal mismatch not only vitiated a positive link between personal goals and achievement-relevant outcomes, but also exacerbated an inimical relation between them. A mitigation mismatch effect was not observed in our research.

With regard to the vitiation mismatch effect, pursuing performance-approach goals in a 
mastery-oriented environment is likely to be a frustrating, rather than enjoyable, experience, because the definition of competence emphasized within this goal structure (task-based or intraindividual) is different from that pursued by students who adopt performance-approach goals (normative). Students who pursue performance-approach goals in mastery-based classrooms may be viewed as antagonistic or self-centered by others, which is likely to be disturbing and distracting. Furthermore, some types of strategies prompted by personal performance-approach goals such as the rote processing of material (Elliot, McGregor, \& Gable, 1999) and the avoidance of help seeking (Ryan, Pintrich, \& Midgley, 2001) may be an awkward fit for the mastery-based classroom. The second mismatch effect is consistent with findings from Lau and Nie (2008), and suggests that the environments that emphasize social comparison put additional pressure on students pursuing performance-avoidance goals. Normative feedback is typically viewed as more diagnostic of ability than other forms of competence information (Elliot, Shell, Henry, \& Maier, 2005; Nicholls, 1989), therefore, for those pursuing performance-avoidance goals, performance-approach goal structures afford the very thing they seek to evade - clear, unambiguous failure feedback.

Together, our results suggest that the joint influence of classroom goal structures and personal goals on achievement-relevant outcomes is not unitary, but multiform. We believe that focusing on only one or two models is problematic, because by doing so researchers are likely to miss the full picture, which may lead to erroneous conclusions. For example, results from the direct effect model showed no relationship between mastery goal structures and academic self-concept independently of personal achievement goals. A researcher might conclude from this finding that focusing on a mastery goal structure in the classroom is of no bearing for students' academic self-concept. However, the null results from the direct effect model must be considered in concert with those from the indirect effect model indicating that mastery goal structures do 
indeed influence students' academic self-concept, but do so indirectly by prompting mastery goal adoption. As another example, results from the interaction effect model showed a match effect for the link between personal performance-approach goals and achievement-relevant outcomes. A researcher might conclude from this finding that performance-approach goals structures are ideal, and need to be promoted by teachers, principals, and administrators. However, the results from the interaction effect model must be interpreted in the context of those from the direct effect model showing that performance-approach goals structures have a negative overall effect on intrinsic motivation and academic self-concept. Therefore, consideration of all three models simultaneously is necessary to acquire a clear picture of the joint influence of classroom goal structures and personal goals on achievement-relevant outcomes.

\section{Limitations and Future Directions}

Our findings must be interpreted in the context of several limitations. First, our research used a concurrent design; therefore, care must be taken to interpret the results in terms of associations rather than causal relations. This consideration highlights the need to attend to reciprocal influences in each of the focal models; it is undoubtedly the case that goal structures not only influence students' adoption of achievement goals, but are also influenced by it. That is, the personal achievement goals that students bring with them into a classroom may, in aggregate, contribute to the classroom ethos, and may also elicit certain types of behavior or instructional practices from teachers which, in turn, influence students' subsequent achievement goal adoption (Urdan, 2004a). Second, we focused on only two self-reported motivational constructs in our research; some researchers recommend using a broader set of outcome variables, because goal structures and personal goals might have selective effects on particular outcome variables (Barron \& Harackiewicz, 2001; Wolters, 2004). We utilized one outcome measure that is widely used in the achievement goal literature (intrinsic motivation) and one that is relatively novel in this 
literature (academic self-concept) in order to focus on both replicating and extending prior findings. However, future work is needed to examine the issues addressed herein using a more extensive set of student outcomes (e.g., performance attainment) with a variety of different methods (e.g., classroom observations).

Third, the generalizability of the current results beyond early adolescents in mathematics classrooms in junior-high and high schools is currently unknown. In addition, our sample was comprised of Japanese students, and some researchers have raised the possibility that achievement goals may operate differently in different cultures (Maehr \& Nicholls, 1980; Urdan \& Mestas, 2006; Zusho \& Njoku, 2007; see Elliot, Chirkov, Sheldon, \& Kim, 2001, for an analogous point regarding approach and avoidance goals more generally). For example, Urdan (2004b) has suggested that performance-based goals may be interpreted differently in individualistic Western cultures and collectivistic Eastern cultures, because these cultures have different conceptions of the self (Markus \& Kitayama, 1991), and performance-based goals often evoke self-reflection and self-evaluation. Although recent psychometric evidence seems to indicate that personal achievement goals are viewed in a relatively similar way across individualistic and collectivistic cultures (Murayama, Zhou, \& Nesbit, in press), care should be taken in generalizing the results of the present research to other cultures.

Fourth, we did not find enough between-classroom variation in the performance-avoidance goal structure to allow inclusion in our analyses. One possibility for this low between-classroom variation is that teachers do not typically emphasize avoiding normative incompetence in the classroom, and this leads to a floor effect (with accompanying restricted variance). This may be especially likely in a Japanese sample, given data indicating that Japanese teachers tend to focus primarily on task mastery and learning (Stigler, Gonzales, Kawanaka, Knoll, \& Serano, 1999). It should be noted that this floor effect may seem plausible at lower 
levels of schooling, but as students advance into the upper levels of high school and college, they undoubtedly encounter at least some aspects of a performance-avoidance goal structure (e.g., Karabenick, 2004), and we believe this is the case even in Japan (see Dore, 1976).

\section{Conclusion}

In closing, during the past two decades, scholars embracing the achievement goal approach to achievement motivation have made a strong case for the conceptual and predictive utility of both personal achievement goals and classroom goal structures. A great deal has been learned about both levels of achievement goal, and this knowledge base clearly has direct and important relevance to real world educational settings. However, much of the research to date has focused on personal goals or goal structures, rather than the joint influence of both levels of goal on student outcomes. It is certainly understandable for the first generation of research on achievement goals to adopt an either/or focus with regard to these two levels of goal, but we believe it is time to move to a second generation of research that considers, in depth, how personal and structural achievement goals work in concert to impact achievement-relevant outcomes. Indeed, more broadly, we believe that the time has come for a focus on the integration of constructs both within and beyond the achievement goal literature, in the interest of moving toward a more comprehensive portrait of achievement motivation. 


\section{References}

Ames, C. (1992). Classrooms: Goals, structures, and student motivation. Journal of Educational Psychology, 84, 261-271.

Ames, C., \& Archer, J. (1988). Achievement goals in the classroom: Students' learning strategies and motivation processes. Journal of Educational Psychology, 80, 260-267.

Anderman, E. M., Anderman, L. H., \& Griesinger, T. (1999). The relation of present and possible academic selves during early adolescence to grade point average and achievement goals. Elementary School Journal, 100, 3-17.

Anderman, E. M., Eccles, J. S., Yoon, K. S., Roeser, R. W., Wigfield, A., \& Blumenfeld, P. C. (2001). Learning to value math and reading: Individual differences and classroom effects. Contemporary Educational Psychology, 26, 76-95.

Anderman, E. M., \& Midgley, C. (1997). Changes in achievement goal orientations, perceived academic competence, and grades across the transition to middle-level schools. Contemporary Educational Psychology, 22, 269-298.

Anderman, E. M., \& Midgley, C. (2002). Methods for studying goals, goal structures, and patterns of adaptive learning. In C. Midgley (Ed.), Goals, goal structures, and patterns of adaptive learning (pp. 1-20). Mahwah, NJ: Erlbaum.

Anderman, E. M., \& Young, A. J. (1994). Motivation and strategy use in science:

Individual-differences and classroom effects. Journal of Research in Science Teaching, 31, 811-831.

Anderman, L. H., Patrick, H., Hruda, L. Z., \& Linnenbrink, E. A. (2002). Observing classroom goal structures to clarify and expand goal theory. In C. Midgley (Ed.), Goals, goal structures, and patterns of adaptive learning (pp. 243-278). Mahwah, NJ: Lawrence Erlbaum. 
Barron, K. E. \& Harackiewicz, J. M. (2001). Achievement goals and optimal motivation: Testing multiple goal models. Journal of Personality and Social Psychology, 80, 706-722.

Bauer, D. J., \& Curran, P. J. (2005). Probing interactions in fixed and multilevel regression: Inferential and graphical techniques. Multivariate Behavioral Research, 40, 373-400.

Bong, M. (2005). Within-grade changes in Korean girls' motivation and perceptions of the learning environment across domains and achievement levels. Journal of Educational Psychology, 97, 656-672.

Bretz, R. D., \& Judge, T. A. (1994). The role of human-resource systems in job applicant decision-processes. Journal of Management, 20, 531-551.

Carver, C. S. \& Scheier, M. F. (1981). Attention and self-regulation: A control-theory approach to human behavior. New York: Springer-Verlag.

Church, M. A. Elliot, A. J. \& Gable, S. L. (2001). Perceptions of classroom environment, achievement goals, and achievement outcomes. Journal of Educational Psychology, 93, 43-54.

Covington, M. V., \& Omelich, C. L. (1984). Task-oriented versus competitive learning structures: Motivational and performance consequences. Journal of Educational Psychology, 76, 1038-1050.

Cronbach, L. J., \& Snow, R. E. (1981). Aptitudes and instructional methods: A handbook for research on interactions. New York: Irvington.

Cury, F., Elliot, A. J., Da Fonseca, D., \& Moller, A. (2006). The social-cognitive model of achievement motivation and the 2 x 2 achievement goal framework. Journal of Personality and Social Psychology, 90, 666-679.

Cury, Elliot, Sarrazin, Da Fonseca, \& Rufo (2002). The trichotomous achievement goal model and intrinsic motivation: A sequential mediational analysis. Journal of Experimental Social 
Psychology, 38, 473-481.

Deci, E. L. (1971). Effects of externally mediated rewards on intrinsic motivation. Journal of Personality and Social Psychology, 18, 105-115.

De Fraine, B., Van Damme, J., \& Onghena, P. (2007). A longitudinal analysis of gender differences in academic self-concept and language achievement: A multivariate multilevel latent growth approach. Contemporary Educational Psychology, 32, 132-150.

Dore, R. P. (1976). The diploma disease: Education, qualification, and development. London: George Allen \& Unwin Ltd.

Durik, A. M., \& Harackiewicz, J. M. (2003). Achievement goals and intrinsic motivation: Coherence, concordance, and achievement orientation. Journal of Experimental Social Psychology, 39, 378-385.

Dweck, C. S. (1986). Motivational process affects learning. American Psychologist, 41, 1010-1018.

Dweck, C. S. (1999). Self-theories: Their role in motivation, personality, and development. Philadelphia, PA: Psychology Press.

Dweck, C. S., \& Leggett, E. L. (1988). A social-cognitive approach to motivation and personality. Psychological Review, 95, 256-273.

Eccles, J., \& Midgley, C. (1989). Stage/environment fit: Developmentally appropriate classrooms for young adolescents. In R. E. Ames \& C. Ames (Eds.), Research on motivation and education (Vol. 3, pp. 139-186). New York: Academic Press.

Eccles, J., Midgley, C., Buchanan, C., Wigfield, A., Reuman, D., \& MacIver, D. (1993). Development during adolescence: The impact of stage/environment fit on young Adolescents' experiences in schools and families. American Psychologist, 48, 90-101.

El-Alayli, A. (2006). Matching achievement contexts with implicit theories to maximize 
motivation after failure: A congruence model. Personality and Social Psychology Bulletin, 32, 1690-1702.

Elliot, A. (1997). Integrating the "classic" and "contemporary" approaches to achievement motivation: A hierarchical model of approach and avoidance achievement motivation. In M. Maehr \& P. Pintrich (Eds.), Advances in motivation and achievement (pp. 143-179). Greenwich, CT: JAI.

Elliot, A. (1999). Approach and avoidance motivation and achievement goals. Educational Psychologist, 34, 149-169.

Elliot, A. J. (2005). A conceptual history of the achievement goal construct. In A. J. Elliot \& C. Dweck (Eds.), Handbook of competence and motivation (pp. 52-72). New York: Guilford Press.

Elliot, A. J. (2006). The hierarchical model of approach-avoidance motivation. Motivation and Emotion, 30, 111-116.

Elliot, A. J., Chirkov, V. I., Sheldon, K. M., \& Kim, Y. (2001). A cross-cultural analysis of avoidance (relative to approach) personal goals. Psychological Science, 12, 505-510.

Elliot, A. J. \& Church, M. A. (1997). A hierarchical model of approach and avoidance achievement motivation. Journal of Personality and Social Psychology, 72, 218-232.

Elliot, A. J., \& Harackiewicz, J. M. (1994). Goal setting, achievement orientation, and intrinsic motivation: A mediational analysis. Journal of Personality and Social Psychology, 66, 968-980.

Elliot, A. J., \& Harackiewicz, J. M. (1996). Approach and avoidance achievement goals and intrinsic motivation: A mediational analysis. Journal of Personality and Social Psychology, $70,461-475$. 
Elliot, A. J., McGregor, H. A., \& Gable, S. (1999). Achievement goals, study strategies, and exam performace: A mediational analysis. Journal of Educational Psychology, 91, $549-563$.

Elliot, A. J., \& McGregor, H. A. (2001). A 2×2 achievement goal framework. Journal of Personality and Social Psychology, 80, 501-519.

Elliot, A. J., \& Moller, A. (2003). Performance-approach goals: Good or bad forms of regulation? International Journal of Educational Research, 39, 339-356.

Elliot, A. J., Shell, M. M., Henry, K, \& Maier, M. (2005). Achievement goals, performance contingencies, and performance attainment: An experimental test. Journal of Educational Psychology, 97, 630-640.

Enders, C. K., \& Tofighi, D. (2007). Centering predictor variables in cross-sectional multilevel models: A new look at an old issue. Psychological Methods, 12, 121-138.

Epstein, J. L. (1988). Effective schools or effective students: Dealing with diversity. In R. Haskins \& D. Macrae (Eds.), Policies for America's public schools: Teachers, equity, and indicators (pp. 89-126). Norwood, NJ: Ablex.

Gottfried, A. E., Fleming, J. S., \& Gottfried, A. W. (2001). Continuity of academic intrinsic motivation from childhood through late adolescence: A longitudinal study. Journal of Educational Psychology, 93, 3-13.

Greene, B. A., Miller, R. B., Crowson, H. M., Duke, B. L., \& Akey, K. L. (2004). Predicting high school students' cognitive engagement and achievement: Contributions of classroom perceptions and motivation. Contemporary Educational Psychology, 29, 462-482.

Gutman, L. M. (2006). How student and parent goal orientations and classroom goal structures influence the math achievement of African Americans during the high school transitions. Contemporary Educational Psychology, 31, 44-63. 
Harackiewicz, J. M., Barron, K. E., \& Elliot, A. J. (1998). Rethinking achievement goals: When are they adaptive for college students and why? Educational Psychologist, 33, 1-21.

Harackiewicz, J. M, Barron, K. E., Elliot, A. J., Carter, S. M., \& Lehto, A. T. (1997). Predictors and consequences of achievement goals in the college classroom: Maintaining interest and making the grade. Journal of Personality and Social Psychology, 73, 1284-1295.

Harackiewicz, J. M., \& Elliot, A. J. (1993). Achievement goals and intrinsic motivation. Journal of Personality and Social Psychology, 65, 904-915.

Harackiewicz, J. M., \& Elliot, A. J. (1998). The joint effects of target and purpose goals on intrinsic motivation: A mediational analysis. Personality and Social Psychology Bulletin, 24, 675-689.

Harackiewicz, J. M., \& Sansone, C. (1991). Goals and intrinsic motivation: You can get to there from here. In M. L. Maehr \& P. R. Pintrich (Eds.), Advances in motivation and achievement (Vol. 7, pp. 21-49). Greenwich, CT: JAI Press.

Harrison, D. A., \& McLaughlin, M. E. (1993). Cognitive processes in self-report responses: Tests of item context effects in work attitude measures. Journal of Applied Psychology, 78, 129-140.

Harter, S. (1981). A new self-report scale of intrinsic versus extrinsic orientation in the classroom: Motivational and informational components. Developmental Psychology, 17, 300-312.

Heyman, G. D., \& Dweck, C. S. (1992). Achievement goals and intrinsic motivation: Their relation and their role in adaptive motivation. Motivation and Emotion, 16, 231-247.

Higgins, E. T. (2000). Making a good decision: Value from fit. American Psychologist, 55, 1217-1230.

Hofmann, D. A., Griffin, M. A., \& Gavin, M. B. (2000). The application of hierarchical linear 
modeling to organizational research. In K. J. Klein \& S. W. Kozlowski (Eds.). Multilevel theory, research, and methods in organizations: Foundations, extensions, and new directions (pp. 467-511). San Francisco: Jossey-Bass.

Hox, J. J. (1993). Factor analysis of multilevel data: Gauging the Muthen model. In J. H. L. Oud \& R. A. W. van Blokland-Vogelesang (Eds.), Advances in longitudinal and multivariate analysis in the behavioral sciences (pp. 141-156). Nijmegen, NL: ITS.

Hunt, D. E. (1975). Person-environment interaction: A challenge found wanting before it was tried. Review of Educational Research, 45, 209-230.

Hyde, J. \& Durik, A. (2005). Gender, competence and self-regulation. In A. J. Elliot \& C. S. Dweck (Eds.), Handbook of competence and self-regulation (pp. 375-391). New York, London: The Guilford Press.

Ichihara, M..\& Arai, K. (2004a). The development of academic perceived competence and intrinsic interest: A cross-sectional study in grade 4 through 9 students. Tsukuba Psychological Research, 27, 43-50.

Ichihara, M \& Arai, K. (2004b). The relation of self-confidence and academic achievement in academic setting. World Congress of Behavioral and Cognitive Therapies, 282.

Kaplan, A., Gheen, M., \& Midgley, C. (2002). Classroom goal structure and student disruptive behavior. British Journal of Educational Psychology, 72, 191-211.

Kaplan, A., \& Maehr, M. L. (1999). Achievement goals and student well-being. Contemporary Educational Psychology, 24, 330-358.

Kaplan, A., \& Maehr, M. L. (2007). The contributions and prospects of goal orientation theory. Educational Psychology Review, 19, 141-184.

Kaplan, A., Middleton, M., Urdan, T. and Midgley, C. (2002). Achievement goals and goal structures. In. C. Midgley (Ed. ), Goals, goal structures, and patterns of adaptive learning 
(pp. 21-53). Mahwah, NJ: Erlbaum.

Kaplan, A., \& Midgley C. (1999). The relationship between perceptions of the classroom goal structure and early adolescents' affect in school: The mediating role of coping strategies. Learning and Individual Differences, 11, 187-212.

Karabenick, S. A. (2004). Perceived achievement goal structure and college student help seeking. Journal of Educational Psychology, 96, 569-581.

Kenney, D. A. \& La Voie, L. (1985). Separating individual and group effects. Journal of Personality and Social Psychology, 48, 339-348.

Knowles, E. S. (1988). Item context effects on personality scales: Measuring changes the measure. Journal of Personality and Social Psychology, 55, 312-320.

Kristof-Brown, A. L. \& Stevens, C. K. (2001). Goal congruence in project teams: Does the fit between members' personal mastery and performance goals matter? Journal of Applied Psychology, 86, 1083-1095.

Krull, J. L., \& MacKinnon, D. P. (1999). Multilevel mediation modeling in group-based intervention studies. Evaluation Review, 23, 418-444.

Krull, J. L., \& MacKinnon, D. P. (2001). Multilevel modeling of individual and group level mediated effects. Multivariate Behavioral Research, 36, 249-277.

Kumar, R. (2006). Students' experiences of home-school dissonance: The role of school academic culture and perceptions of classroom goal structures. Contemporary Educational Psychology, 31, 253-279.

Lau, S., \& Nie, Y. (2008). Interplay between personal goals and classroom goal structures in predicting student outcomes: A multilevel analysis of person-context interactions. Journal of Educational Psychology, 100, 15-29.

Lepper, M. R. (1981). Intrinsic and extrinsic motivation in children: Detrimental effects of 
superfluous social controls. In W. A. Collins, (Ed.), Minnesota symposium on child psychology (Vol. 14, pp. 155-214). Hillsdale, NJ: Lawrence Erbaum Associates.

Lewin, K. (1935). A dynamic theory of personality. New York: McGraw-Hill.

Lewin, K., Dembo, T., Festinger, L., \& Sears, P. (1944). Level of aspiration. In J. M. Hunt (Ed.). Personality and the behavior disorders (pp. 333-378). Oxford: Ronald Press.

Linnenbrink, E. A. (2004). Person and context: Theoretical and practical concerns in achievement goal theory. In P. R. Pintrich \& M. L. Maehr (Eds.), Advances in motivation and achievement: Motivating students, improving schools: The legacy of Carol Midgley (Vol. 13, pp. 159-184). Greenwich, CT: JAI.

Linnenbrink, E. A. (2005). The dilemma of performance-approach goals: The use of multiple goal contexts to promote students' motivation and learning. Journal of Educational Psychology, 97, 197-213.

Linnenbrink, E. A., \& Pintrich, P. R. (2001). Multiple goals, multiple contexts: The dynamic interplay between personal goals and contextual goal stresses. In S. Volet \& S. Järvelä (Eds.), Motivation in learning contexts: Theoretical and methodological implications (pp. 251-269). Amsterdam: Pergamon Press.

Little, R. J. A. \& Rubin, D. B. (1987). Statistical Analysis with Missing Data. New York: John Wiley.

Liu, W. C.; Wang, C. K. J., \& Parkins, E. J. (2005). A longitudinal study of students' academic self-concept in a streamed setting: The Singapore context. British Journal of Educational Psychology. 75, 567-586.

Maehr, M.L. (1984). Meaning and motivation: Toward a theory of personal investment. In R. Ames \& C. Ames (Eds.), Research on motivation in education (Vol. 1, pp. 115-144). New York: Academic Press. 
Maehr, M. L., \& Midgley, C. (1991). Enhancing student motivation: A schoolwide approach. Educational Psychologist, 26, 399-427.

Maehr, M. L., \& Midgley, C. (1996). Transforming school cultures. Boulder, CO: Westview Press.

Maehr, M. L., \& Nicholls, J. G. (1980). Culture and achievement motivation: A second look. In N. Warren (Ed.), Studies in cross-cultural psychology (Vol. 2, pp. 221-267). New York: Academic Press.

Markus, H. R., \& Kitayama, S. (1991). Culture and the self: Implications for cognition, emotion, and motivation. Psychological Review, 98, 224-253.

Marsh, H. W. (1989). Age and sex effects in multiple dimensions of self-concept: Preadolescence to early adulthood. Journal of Educational Psychology, 81, 417-430.

Marsh, H. W. (1990). The structure of academic self-concept: The Marsh/Shavelson model. Journal of Educational Psychology, 82, 623-636.

Marsh, H. W., \& Hau, K. T. (2003). Big-fish-little-pond effect on academic self-concept: A cross-cultural (26 country) test of the negative effects of academically selective schools. American Psychologist, 58, 364-376.

Marsh, H. W., \& Yeung, A. S. (1998). Longitudinal structural equation models of academic self-concept and achievement: Gender differences in the development of math and English constructs. American Educational Research Journal, 35, 705-738.

McDonald, R. P. (1999). Test theory: A unified treatment. Mahwah, NJ: Lawrence Erlbaum.

Meece, J., Anderman E. M., \& Anderman, L. H. (2006). Structures and goals of educational settings: Classroom goal structure, student motivation, and academic achievement. Annual Review of Psychology, 57, 487-504.

Meece, J. L., Parsons, J. E., Kaczala, C. M., Goff, S. B., \& Futterman, R. (1982). Sex differences 
in math achievement: Toward a model of academic choice. Psychological Bulletin, 91, 324-348.

Middleton, M. J., Gheen, M., Midgley, C., Hruda, L., \& Anderman, E. (2000). Approach and avoid goal structures: Relating classroom and personal goal orientations. Paper delivered at the annual meeting of the American Psychological Association, Washington, DC.

Midgley, C., Anderman, E., \& Hicks, L. (1995). Differences between elementary and middle school teachers and students: A goal theory approach. Journal of Early Adolescence, 15, 90-113.

Midgley, C., Maehr, M. L., Hruda, L. Z., Anderman, E., Anderman, L., Freeman, K. E., Gheen, M., Kaplan, A., Kumar, R., Middleton, M. J., Nelson, J., Roeser, R., \& Urdan, T., (2000). Manual for the patterns of adaptive learning scales (PALS). Ann Arbor, MI: University of Michigan.

Midgley, C., \& Urdan, T. (1995). Predictors of middle school students' use of self-handicapping strategies. Journal of Early Adolescence, 15, 389-411.

Midgley, C., \& Urdan, T. (2001). Academic self-handicapping and achievement goals: A further examination. Contemporary Educational Psychology, 26, 61-75.

Miki, K., \& Yamauchi, H. (2005). Perceptions of classroom goal structures, personal achievement goal orientations, and learning strategies. Japanese Journal of Psychology, 76, 260-268.

Miller, R. B., Greene, B. A., Montalvo, G. P., Ravindran, B., \& Nichols, J. D. (1996). Engagement in academic work: The role of learning goals, future consequences, pleasing others, and perceived ability. Contemporary Educational Psychology, 21, 388-422.

Miller, A. D., \& Murdock, T. B. (2007). HLM models for estimating the reliability of classroom context variables: The assessment of classroom goal structures. Contemporary Educational Psychology, 32, 83-104. 
Murayama, K., Zhou, M., \& Nesbit, J. C. (in press). A cross-cultural examination of the psychometric properties of responses to the Achievement Goal Questionnaire. Educational and Psychological Measurement.

Murray, H. A. (1938). Explorations in personality. New York: Oxford University Press.

Muthen, B. O. (1994). Multilevel covariance structure analysis. Sociological Methods and Research, 22, 376-398.

Nicholls, J. G. (1989). The competitive ethos and democratic education. Cambridge, MA: Harvard University Press.

Nolen, S. B. (2003). Learning environment, achievement, and motivation in high school science. Journal of Research in Science Teaching, 40, 347-368.

Nolen, S. B., \& Haladyna, T. M. (1990). Personal and environment influences on students' beliefs about effective study strategies. Contemporary Educational Psychology, 15, 116-130.

Oishi, S., Diener, E., Suh, E., \& Lucas, R. E. (1999). Value as a moderator in subjective well-being. Journal of Personality, 67, 157-184.

Organisation for Economic Cooperative Development (2004). Learning for tomorrow's world: First results from PISA 2003. Paris: OECD.

Otis, N., Grouzet, F. M. E., \& Pelletier, L. G. (2005). Latent motivational change in an academic setting: A 3-year longitudinal study. Journal of Educational Psychology, 97, 170-183.

Pajares, F., Britner, S. L., \& Valiante, G. (2000). Relation between achievement goals and self-beliefs of middle school students in writing and science. Contemporary Educational Psychology, 25, 406-422.

Pajares, F., \& Cheong, Y. F. (2003). Achievement goal orientations in writing: A developmental perspective. International Journal of Educational Research, 39, 437-455.

Patrick, H., Ryan, A. M., \& Kaplan, A. (2007). Early adolescents' perceptions of the classroom 
social environment, motivational beliefs, and engagement. Journal of Educational Psychology, 99, 83-98.

Payne, S. C., Youngcourt, S. S., \& Beaubien, J. M. (2007). A meta-analytic examination of the goal orientation nomological net. Journal of Applied Psychology, 92, 128-150.

Pintrich, P. R., \& Garcia, T. (1991). Student goal orientation and self-regulation in the college classroom. In M. L. Maehr \& P. R. Pintrich (Eds.), Advances in motivation and achievement (Vol. 7, pp. 371-402). Greenwich, CT: JAI Press.

Pintrich, P. R., \& Schunk, D. H. (2002). Motivation in education: Theory, research, and practice. Englewood Cliffs, NJ: Merrill.

Podsakoff, P. M., MacKenzie, S. M., Lee, J., \& Podsakoff, N. P. (2003). Common method variance in behavioral research: A critical review of the literature and recommended remedies. Journal of Applied Psychology, 88, 879-903.

Raudenbush, S. W., \& Bryk, A. S. (2002). Hierarchical linear models: Applications and data analysis methods (2nd ed.). Newbury Park, CA: Sage.

Raudenbush, S. W., Bryk, A. S., Cheong, Y. F., \& Congdon, R. T. (2004). HLM 6: Hierarchical linear and nonlinear modeling. Lincolnwood, IL: Scientific Software International, Inc.

Rawsthorne, L. J., \& Elliot, A. J. (1999). Achievement goals and intrinsic motivation: A meta-analytic review. Personality and Social Psychology Review, 3, 326-344.

Roeser, R. W., Midgley, C., \& Urdan, T. C. (1996). Perceptions of the school psychological environment and early adolescents' psychological and behavioral functioning in school: The mediating role of goals and belonging. Journal of Educational Psychology, 88, 408-422.

Ryan, A. M., Gheen, M. H., \& Midgley, C. (1998). Why do some students avoid asking for help? An examination of the interplay among students' academic efficacy, teachers' 
social-emotional role, and the classroom goal structure. Journal of Educational Psychology, 90, 528-535.

Ryan, A. M., \& Patrick, H. (2001). The classroom social environment and changes in adolescents' motivation and engagement during middle school. American Educational Research Journal, $38,437-460$.

Ryan, A. M., Pintrich, P. R., \& Midgley, C. (2001). Avoiding seeking help in the classroom: Who and why? Educational Psychology Review, 13, 93-113.

Sansone, C. (1989). Competence feedback, task feedback, and intrinsic interest: An examination of process and context. Journal of Experimental Social Psychology, 25, 343-361.

Schafer, J. L. (1997) Analysis of incomplete multivariate data. Chapman \& Hall, London.

Schafer, J. L., \& Graham, J. W. (2002). Missing data: our view of the state of the art. Psychological Methods, 7, 147-177.

Skaalvik, E. M. (1997). Self-enhancing and self-defeating ego orientation: Relations with task and avoidance orientation, achievement, self-perceptions, and anxiety. Journal of Educational Psychology, 89, 74-81.

Sobel, M. E. (1982). Asymptotic confidence intervals for indirect effects in structural equation models. In S. Leinhardt (Ed.), Sociological methodology 1982 (pp. 290-312). Washington, DC: American Sociological Association.

Spencer, S. J., Steele, C. M., \& Quinn, D. M. (1999). Stereotype threat and women's math performance. Journal of Experimental Social Psychology, 35, 4-28.

Stigler, J. W.; Gonzales, P.; Kawanaka, T.; Knoll, S. \& Serano, A. (1999). The TIMSS videotape classroom study: Methods and findings from an exploratory research project on eighth-grade mathematics instruction in Germany, Japan and the United States. Washington D.C.: U.S. Government Printing Office. 
Sudman, S., Bradburn, N.M., \& Schwarz, N. (1996). Thinking about answers: The application of cognitive processes to survey methodology. San Francisco: Jossey-Bass.

Tanaka, A., \& Yamauchi, H. (2000). Causal models of achievement motive, goal orientation, intrinsic interest, and academic achievement in classroom. Japanese Journal of Psychology, 71, 317-324.

Tanaka, A., \& Yamauchi, H. (2001). A model for achievement motives, goal orientations, intrinsic interest, and academic achievement. Psychological Reports, 88, 123-135.

Tate, R. (2004). Interpreting hierarchical linear and hierarchical generalized models with slopes as outcomes. Journal of Experimental Education, 73, 71-95.

Toyama, M. (2006). Improved academic performance in junior high school students: Comparison targets' academic performance and perceived academic competence. Japanese Journal of Educational Psychology, 54, 55-62.

Turner, J. C., Midgley, C., Meyer, D. K., Gheen, M., Anderman, E. M., Kang, Y., \& Patrick, H. (2002). The classroom environment and students' reports of avoidance strategies in mathematics: A multimethod study. Journal of Educational Psychology, 94, 88-106.

Urdan, T. C. (1997). Achievement goal theory: Past results, future directions. In M. L. Maehr \& P. R. Pintrich (Eds.) Advances in motivation and achievement (vol. 10, pp. 99-141). Greenwich, CT: JAI Press.

Urdan, T. C. (2001). Contextual influences on motivation and performance: An examination of achievement goal structures. In F. Salili, C. Chiu, \& Y. Hong (Eds.), Student motivation: The culture and context of learning (pp. 171-201). New York: Kluwer Academic.

Urdan, T. (2004a). Can achievement goal theory guide school reform? In P. R. Pintrich \& M. L. Maehr (Eds.), Advances in motivation and achievement (vol. 13, pp. 361-392). Greenwich, CT: JAI press. 
Urdan, T. (2004b). Predictors of academic self-handicapping and achievement: examining achievement goals, classroom goal structures, and culture. Journal of Educational Psychology, 96, 251-264.

Urdan, U. (2004c). Using multiple methods to assess students' perceptions of classroom goal structures. European Psychologist, 9, 222-231.

Urdan, T., \& Mestas, M. (2006). The goals behind performance goals. Journal of Educational Psychology, 98, 354-365.

Urdan, T., \& Midgley, C. (2003). Changes in the perceived classroom goal structure and pattern of adaptive learning during early adolescence. Contemporary Educational Psychology, 28, 524-551.

Urdan, T., Midgley, C., \& Anderman, E. M. (1998). The role of classroom goal structure in students' use of self-handicapping strategies. American Educational Research Journal, 35, 101-122.

Urdan, T., \& Turner, J. C. (2005). Competence motivation in the classroom. In A. J. Elliot \& C. S. Dweck (Eds.), Handbook of competence and motivation (pp. 297-317). New York: The Guilford Press.

Vansteenkiste, M., Simons, J., Lens, W., Sheldon, K. M., \& Deci, E. L. (2004). Motivating learning, performance, and persistence: The synergistic effects of intrinsic goal contents and autonomy-supportive contexts. Journal of Personality and Social Psychology, 87, 246-260.

Wolters, C. A. (2004). Advancing achievement goal theory: Using goal structures and goal orientations to predict students' motivation, cognition, and achievement. Journal of Educational Psychology, 96, 236-250.

Yamauchi, H. \& Miki, K. (2003). Longitudinal analysis of the relations between. perceived 
learning environment, achievement goal orientations, and learning strategies: Intrinsic-extrinsic regulation as mediator. Psychologia, 46, 1-18.

Young, A. J. (1997). I think, therefore I'm motivated: The relations among cognitive strategy use, motivational orientation and classroom perceptions over time. Learning and Individual Differences, 9, 249-283.

Zusho, A., \& Njoku, H. (2007). Culture and motivation to learn: Exploring the generalizability of achievement goal theory. In F. Salili \& R. Hoosain (Eds.), Culture, motivation, and learning: A multicultural perspective (pp. 91-113). Charlotte, NC: Information Age Publishing.

Zusho, A., Pintrich, P. R., \& Cortina, K. S. (2005). Motives, goals, and adaptive patterns of performance in Asian American and Anglo American students. Learning and Individual Differences, 15, 141-158. 
Footnotes

1. Elliot and colleagues (Elliot, 1999; Elliot \& McGregor, 2001) have also added a fourth achievement goal construct, mastery-avoidance goals, which are focused on the avoidance of task-/intrapersonally-based incompetence. Mastery-avoidance goals were not investigated in the present research.

2. We use the term "effect" here and throughout in a noncausal sense to indicate predictive relations. This allows us to evade terminological awkwardness, and has recent precedent (Lau \& Nie, 2008).

3. Due to the hierarchically nested structure of the data (students nested within classrooms), the sample covariance of the data confounds the within-classroom covariance with the between-classroom covariance (Hox, 1993; Muthen, 1994). Student-level constructs should be internally consistent within classrooms, thus, we first calculated the within-classroom covariance matrix according to Kenny and La Voie (1985), and then calculated the coefficient omega on the basis of the within-classroom covariance matrix.

4. In the original scale (Midgley et al., 2000), the performance-approach goal structure was measured by three items and the performance-avoidance goal structure was measured by five items. In this study, we rephrased one of the performance-avoidance goal structure items so that it represented a performance-approach goal structure in the interest of bolstering the reliability of the scale.

5. In Japan, except for public junior high schools, academic rank of schools is available in the form of T-scores. We coded each classroom into three ordered categories according to the T-scores of the school $(1=$ less than $40,2=40-59,3=60$ or more $)$. Classrooms of public junior-high schools are coded as 2 given that no students are selected by entrance examination in these schools. This school academic rank variable did not yield any significant results in 
preliminary analyses, so we omitted it from the final analyses reported in the text.

6. We also included interaction term between mastery and performance-approach goal structures to see how the combination of both goal structures influences the intercepts or slopes. No significant effects were obtained. This was also the case for the test of the direct and indirect effect models. Accordingly, no mention will be made in the text about the combined effects of mastery and performance-approach goal structures. 
Table 1 Descriptive Statistics and Correlations for the Student-level Variables

\begin{tabular}{|c|c|c|c|c|c|c|c|}
\hline & \multirow[b]{2}{*}{$M$} & \multirow[b]{2}{*}{$S D$} & \multicolumn{5}{|c|}{ Correlations } \\
\hline & & & 1. & 2. & 3. & 4. & 5. \\
\hline 1. Personal mastery-approach goals & 3.49 & 0.67 & - & & & & \\
\hline 2. Personal performance-approach goals & 3.12 & 0.94 & .40 & - & & & \\
\hline 3. Personal performance-avoidance goals & 3.23 & 1.06 & .21 & .61 & - & & \\
\hline 4. Intrinsic motivation & 3.22 & 3.47 & .64 & .26 & $.05^{\dagger}$ & - & \\
\hline 5. Academic self-concept & 2.56 & 0.89 & .45 & .35 & $-.02^{\dagger}$ & .47 & - \\
\hline
\end{tabular}

Note. All correlations are within-class level, calculated according to Kenny and La Voie (1985). All correlations are significant at the .01 level, except those marked with a dagger, which are not significant. 
Table 2

Personal Achievement Goals as Predictors of Intrinsic Motivation

\begin{tabular}{ll}
\hline Fixed effects & \\
\hline Intercept $\left(\gamma_{00}\right)$ & $3.43^{* *}$ \\
Classroom-level Predictors of Intercept & \\
\multicolumn{1}{|c}{ School grade $\left(\gamma_{01}\right)$} & $-0.08^{*}$ \\
& \\
Sex $\left(\gamma_{10}\right)$ & -0.03 \\
Personal mastery goals $\left(\gamma_{20}\right)$ & $0.80^{* *}$ \\
Personal performance-approach goals $\left(\gamma_{30}\right)$ & $0.12^{*}$ \\
Personal performance-avoidance goals $\left(\gamma_{40}\right)$ & $-0.16^{* *}$ \\
\hline Random effects & Variance \\
\hline Intercept $\left(u_{0 j}\right)$ & $0.123^{* *}$ \\
Personal performance-approach goals $\left(u_{3 j}\right)$ & $0.017^{*}$ \\
\hline
\end{tabular}

Note. Level 1 models were of the form $Y_{\mathrm{ij}}=\beta_{0 \mathrm{j}}+\beta_{1 \mathrm{j}}(\mathrm{sex})+\beta_{2 \mathrm{j}}$ (personal mastery goals) $+\beta_{3 \mathrm{j}}$ (personal performance-approach goals $)+\beta_{4 \mathrm{j}}$ (personal performance-avoidance goals $)+r_{\mathrm{ij}}$. Level 2 models were of the form $\beta_{0 j}=\gamma_{00}+u_{0 j}, \beta_{1 j}=\gamma_{10}, \beta_{2 j}=\gamma_{20}, \beta_{3 j}=\gamma_{30}+u_{3 j}, \beta_{4 j}=\gamma_{40}$.

$* p<.05 . \quad * * p<.01$. 
Table 3

Personal Achievement Goals as Predictors of Academic Self-Concept

\begin{tabular}{ll}
\hline Fixed effects & \\
\hline Intercept $\left(\gamma_{00}\right)$ & $2.95^{* *}$ \\
Classroom-level Predictors of Intercept & \\
\multicolumn{1}{|c}{ School grade $\left(\gamma_{01}\right)$} & $0.09^{* *}$ \\
Sex $\left(\gamma_{10}\right)$ & $-0.31^{* *}$ \\
Personal mastery goals $\left(\gamma_{20}\right)$ & $0.46^{* *}$ \\
Personal performance-approach goals $\left(\gamma_{30}\right)$ & $0.39^{* *}$ \\
Personal performance-avoidance goals $\left(\gamma_{40}\right)$ & $-0.28^{* *}$ \\
\hline Random effects & \\
\hline Intercept $\left(u_{0 j}\right)$ & Variance \\
Personal performance-approach goals $\left(u_{3 j}\right)$ & $0.033^{*}$ \\
Personal performance-avoidance goals $\left(u_{4 j}\right)$ & $0.036^{* *}$ \\
\hline
\end{tabular}

Note. Level 1 models were of the form $Y_{i j}=\beta_{0 j}+\beta_{1 j}(\operatorname{sex})+\beta_{2 j}$ (personal mastery goals) $+\beta_{3 j}$ (personal performance-approach goals $)+\beta_{4 \mathrm{j}}$ (personal performance-avoidance goals $)+r_{\mathrm{ij}}$. Level 2 models were of the form $\beta_{0 j}=\gamma_{00}+u_{0 j}, \beta_{1 j}=\gamma_{10}, \beta_{2 j}=\gamma_{20}, \beta_{3 j}=\gamma_{30}+u_{3 j}, \beta_{4 j}=\gamma_{40}+u_{4 j}$.

$* p<.05 . \quad * * p<.01$. 
Table 4

Achievement Goal Structures as Classroom-level Predictors of Intercept and Slope for Intrinsic Motivation

\begin{tabular}{|c|c|}
\hline Fixed effects & \\
\hline Intercept $\left(\gamma_{00}\right)$ & $3.42^{* *}$ \\
\hline Classroom-level Predictors of Intercept & \\
\hline School grade $\left(\gamma_{01}\right)$ & $-0.08 *$ \\
\hline Mastery goal structure $\left(\gamma_{02}\right)$ & $1.34^{* *}$ \\
\hline Performance-approach goal structure $\left(\gamma_{03}\right)$ & $-0.63 * *$ \\
\hline $\operatorname{Sex}\left(\gamma_{10}\right)$ & -0.04 \\
\hline Personal mastery goals $\left(\gamma_{20}\right)$ & $0.80 * *$ \\
\hline Personal performance-approach goals $\left(\gamma_{30}\right)$ & $0.11^{*}$ \\
\hline$\underline{\text { Classroom-level Predictors of Slope }}$ & \\
\hline Mastery goal structure $\left(\gamma_{31}\right)$ & $-0.44^{*}$ \\
\hline Performance-approach goal structure $\left(\gamma_{32}\right)$ & $0.36^{*}$ \\
\hline Personal performance-avoidance goals $\left(\gamma_{40}\right)$ & $-0.16^{* *}$ \\
\hline Random effects & Variance \\
\hline Intercept $\left(u_{0 \mathrm{j}}\right)$ & $0.070 * *$ \\
\hline Personal performance-approach goals $\left(u_{3 j}\right)$ & 0.009 \\
\hline
\end{tabular}

Note. Level 1 models were of the form $Y_{i j}=\beta_{0 j}+\beta_{1 j}(\operatorname{sex})+\beta_{2 j}$ (personal mastery goals) $+\beta_{3 j}$ (personal performance-approach goals $)+\beta_{4 \mathrm{j}}$ (personal performance-avoidance goals $)+r_{\mathrm{ij}}$. Level 2 models were of the form $\beta_{0 \mathrm{j}}=\gamma_{00}+\gamma_{01}$ (mastery goal structure) $+\gamma_{00}$ (performance-approach 
goal structure $)+u_{0 j}, \beta_{1 j}=\gamma_{10}, \beta_{2 j}=\gamma_{20}, \beta_{3 j}=\gamma_{30}+\gamma_{31}$ (mastery goal structure) + $\gamma_{32}$ (performance-approach goal structure) $+u_{3 j}, \beta_{4 j}=\gamma_{40}$.

$* p<.05 . \quad * * p<.01$. 
Table 5

Achievement Goal Structures as Classroom-level Predictors of Intercept and Slope for Self-Concept

\begin{tabular}{|c|c|}
\hline Fixed effects & \\
\hline Intercept $\left(\gamma_{00}\right)$ & $2.97 * *$ \\
\hline Classroom-level Predictors of Intercept & \\
\hline School grade $\left(\gamma_{01}\right)$ & -0.10 \\
\hline Mastery goal structure $\left(\gamma_{02}\right)$ & $0.55^{*}$ \\
\hline Performance-approach goal structure $\left(\gamma_{03}\right)$ & $-0.50 * *$ \\
\hline $\operatorname{Sex}\left(\gamma_{10}\right)$ & $-0.31^{* *}$ \\
\hline Personal mastery goals $\left(\gamma_{20}\right)$ & $0.46^{* *}$ \\
\hline Personal performance-approach goals $\left(\gamma_{30}\right)$ & $0.38 * *$ \\
\hline$\underline{\text { Classroom-level Predictors of Slope }}$ & \\
\hline Performance-approach goal structure $\left(\gamma_{32}\right)$ & $0.46^{*}$ \\
\hline Personal performance-avoidance goals $\left(\gamma_{40}\right)$ & $-0.27 * *$ \\
\hline$\underline{\text { Classroom-level Predictors of Slope }}$ & \\
\hline Performance-approach goal structure $\left(\gamma_{42}\right)$ & $-0.38^{*}$ \\
\hline Random effects & Variance \\
\hline Intercept $\left(u_{0 \mathrm{j}}\right)$ & $0.037 * *$ \\
\hline Personal performance-approach goals $\left(u_{3 \mathrm{j}}\right)$ & 0.021 \\
\hline Personal performance-avoidance goals $\left(u_{4 j}\right)$ & $0.027 *$ \\
\hline
\end{tabular}

Note. Level 1 models were of the form $Y_{i j}=\beta_{0 j}+\beta_{1 j}(\operatorname{sex})+\beta_{2 j}$ (personal mastery goals) $+\beta_{3 j}$ 
(personal performance-approach goals $)+\beta_{4 \mathrm{j}}$ (personal performance-avoidance goals $)+\mathrm{r}_{\mathrm{ij}}$. Level 2 models were of the form $\beta_{0 j}=\gamma_{00}+\gamma_{01}$ (mastery goal structure) $+\gamma_{00}$ (performance-approach goal structure $)+u_{0 j}, \beta_{1 j}=\gamma_{10}, \beta_{2 j}=\gamma_{20}, \beta_{3 j}=\gamma_{30}+\gamma_{32}$ (performance-approach goal structure) $+u_{3 j}$, $\beta_{4 j}=\gamma_{40}+\gamma_{42}($ performance-approach goal structure $)+u_{4 j}$.

$* p<.05 . \quad * * p<.01$. 


\section{Figure Caption}

Figure 1. An analytic framework for studying the joint influence of personal achievement goals and classroom goal structures on achievement-relevant outcomes. The panels present the direct effect model (1a), the indirect effect model (1b), and the interaction effect model (1c).

Figure 2. Predicted values for intrinsic motivation as a function of (A) personal performance-approach goals at high and low levels of performance-approach goal structure, and (B) personal performance-approach goals at high and low levels of mastery goal structure. Independent variables were group-mean centered.

Figure 3. Predicted values for academic self-concept as a function of (A) personal performance-approach goals at high and low levels of performance-approach goal structure, and (B) personal performance-avoidance goals at high and low levels of performance-approach goal structure. Independent variables were group-mean centered. 
Figure 1a

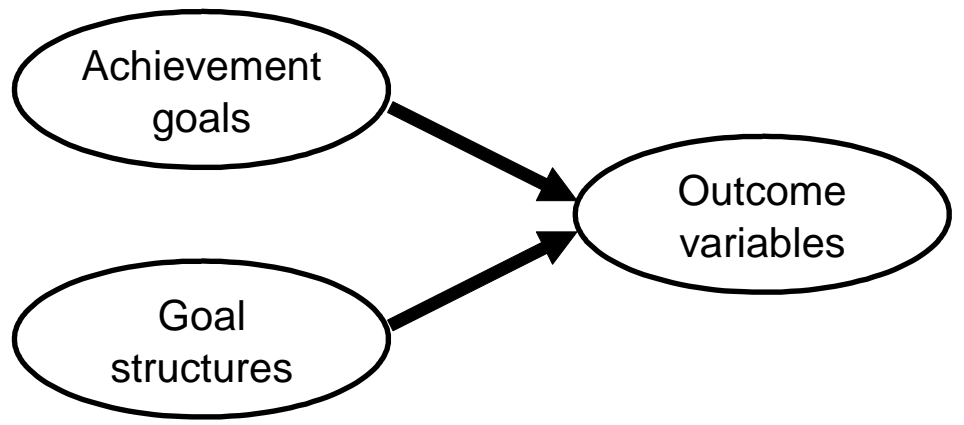

Figure 1b

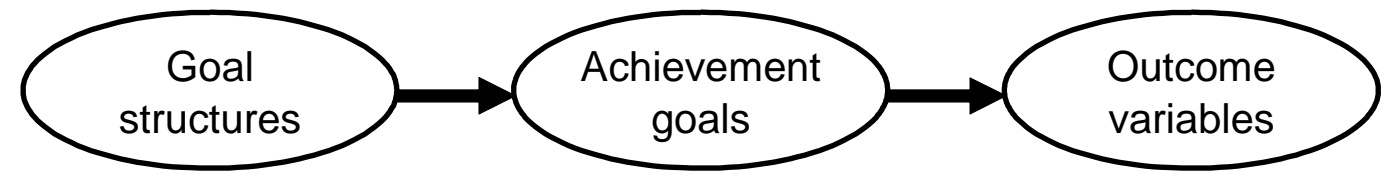

Figure 1c

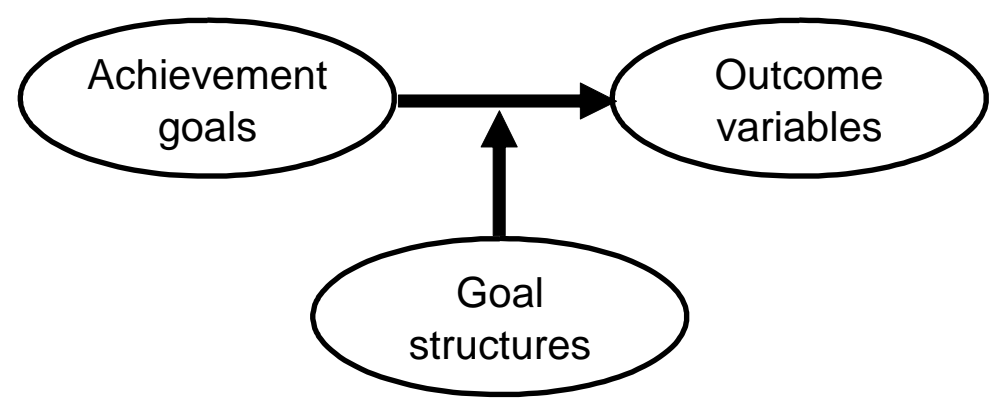


A.

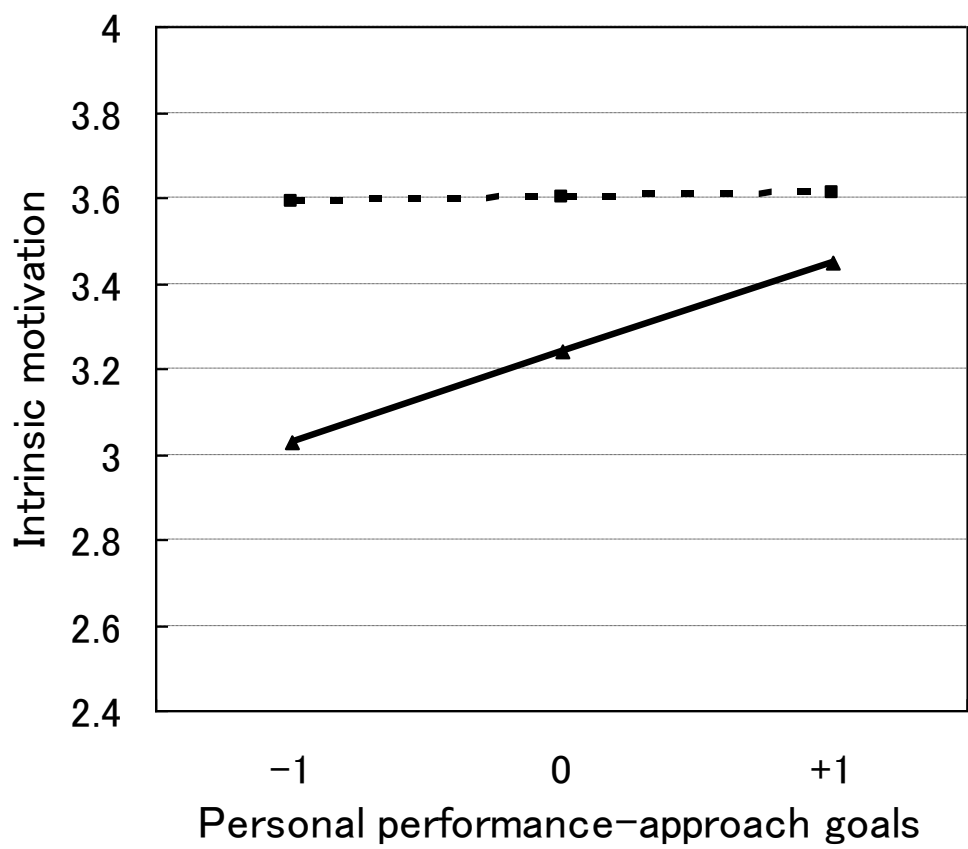
- High performance- approach goal structure
- - Low performance- approach goal structure

B.

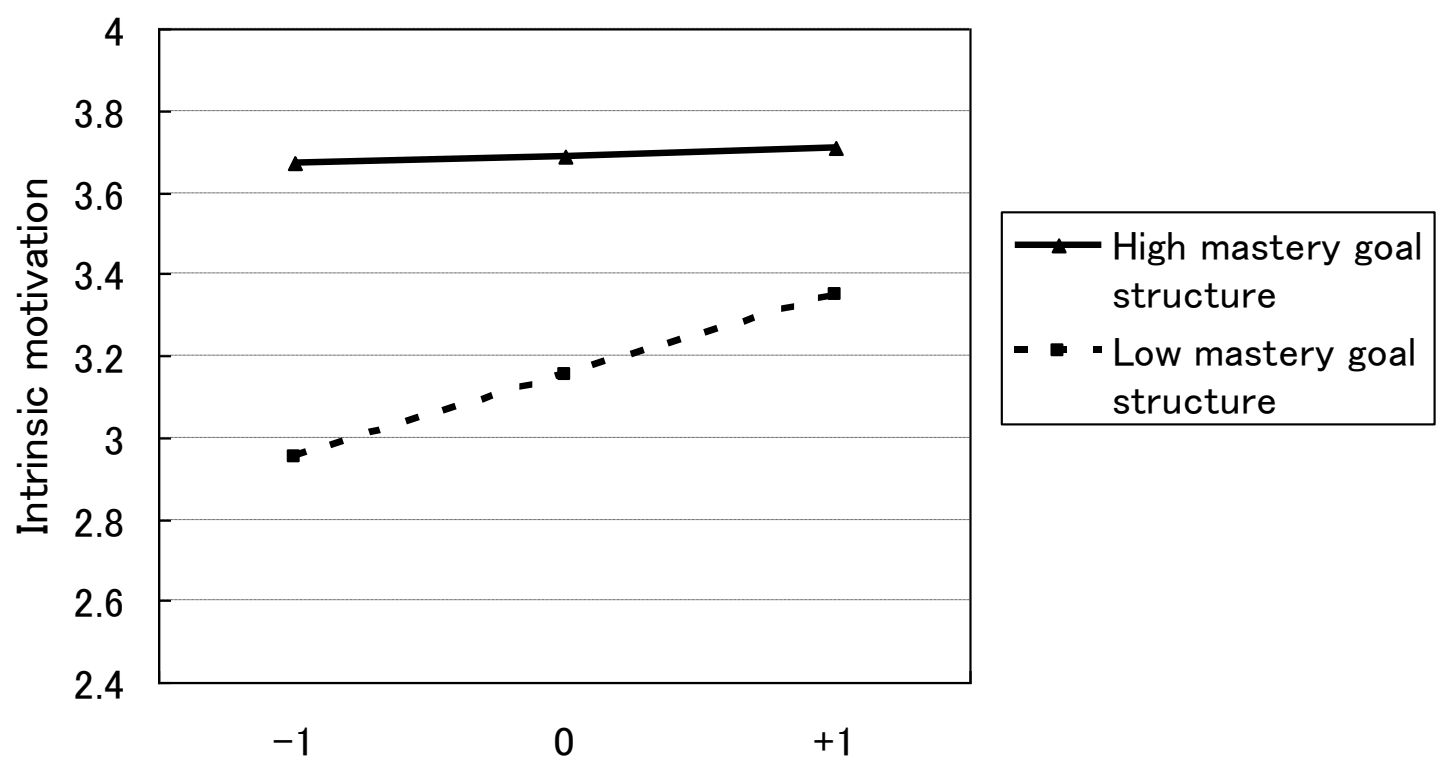

Personal performance-approach goals 
A.

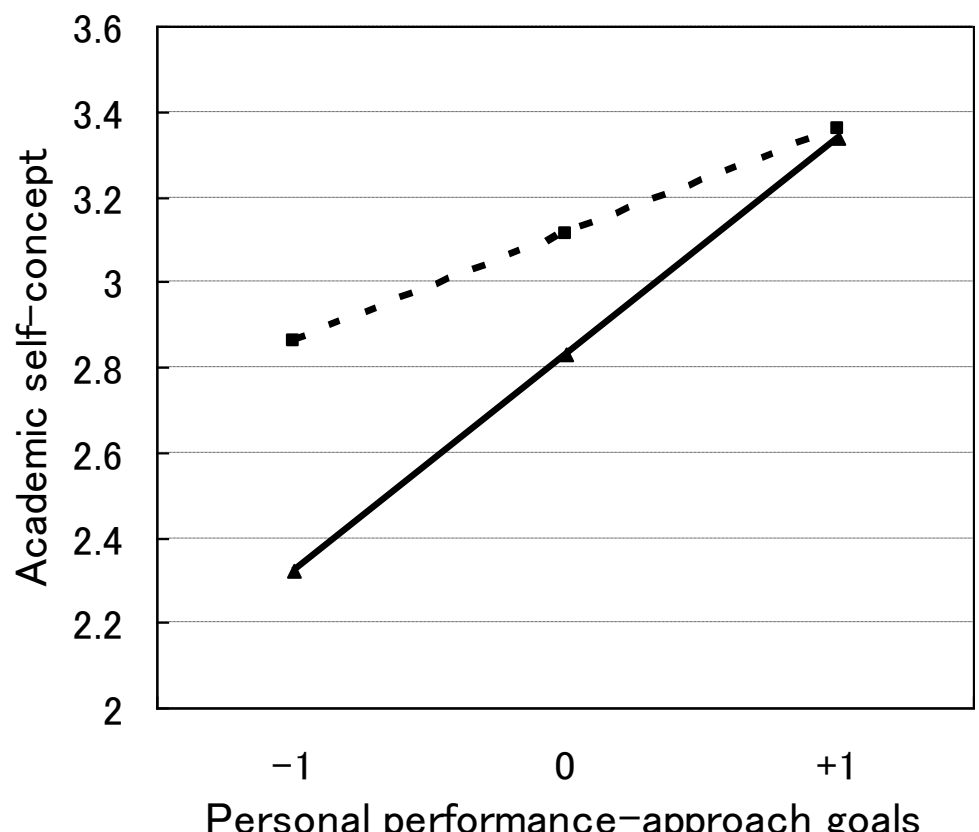
- High performance- approach goal structure
- - Low performance- approach goal structure

B.

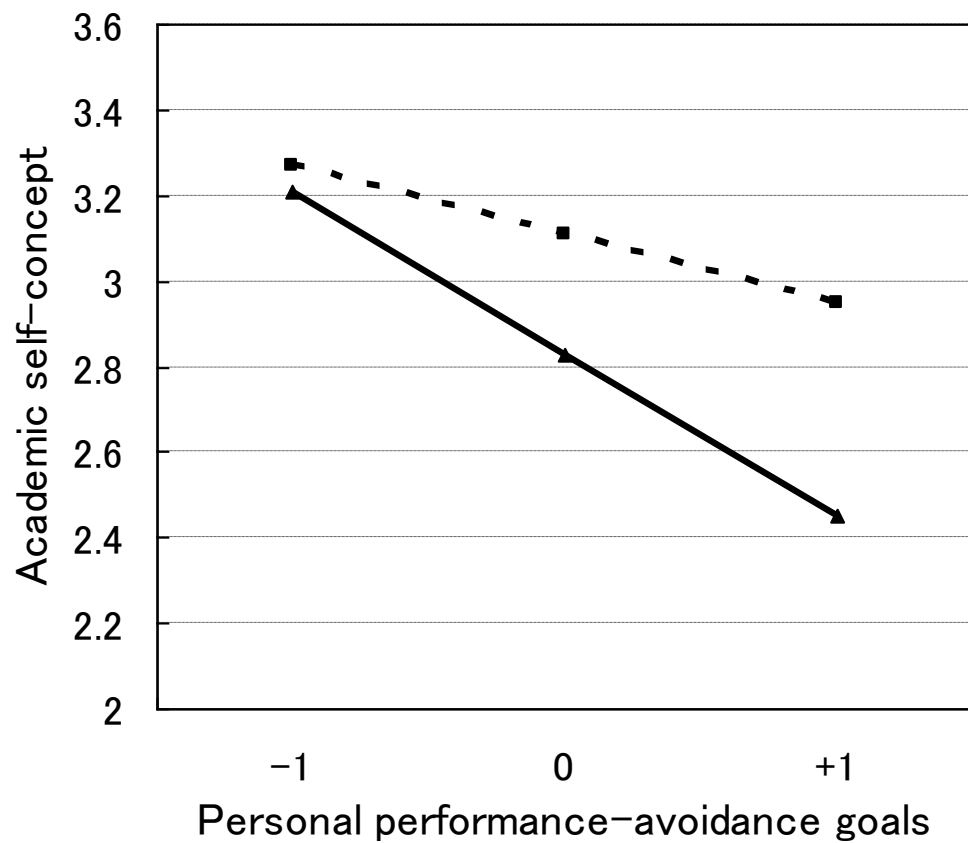
- High performance- approach goal structure
- - Low performance- approach goal structure

